\title{
Cellular Senescence in Liver Disease and Regeneration
}

\author{
Sofia Ferreira-Gonzalez, $\mathrm{PhD}^{1}$ Daniel Rodrigo-Torres, $\mathrm{PhD}^{1} \quad$ Victoria L. Gadd, $\mathrm{PhD}^{1}$ \\ Stuart J. Forbes, MBChB, PhD, FRCP(Ed), FRSE, FMedSci ${ }^{1}$ \\ ${ }^{1}$ MRC Centre for Regenerative Medicine, University of Edinburgh, \\ Edinburgh, United Kingdom \\ Address for correspondence Stuart J. Forbes, MBChB, PhD, FRCP(Ed), \\ FRSE, FMedSci, MRC Centre for Regenerative Medicine, University of \\ Edinburgh, 5 Little France Drive, Edinburgh, EH16 4UU, United \\ Semin Liver Dis 2021;41:50-66. \\ Kingdom (e-mail: stuart.forbes@ed.ac.uk).
}

\section{Abstract \\ Keywords \\ - senescence \\ - liver disease \\ - liver regeneration}

Cellular senescence is an irreversible cell cycle arrest implemented by the cell as a result of stressful insults. Characterized by phenotypic alterations, including secretome changes and genomic instability, senescence is capable of exerting both detrimental and beneficial processes. Accumulating evidence has shown that cellular senescence plays a relevant role in the occurrence and development of liver disease, as a mechanism to contain damage and promote regeneration, but also characterizing the onset and correlating with the extent of damage. The evidence of senescent mechanisms acting on the cell populations of the liver will be described including the role of markers to detect cellular senescence. Overall, this review intends to summarize the role of senescence in liver homeostasis, injury, disease, and regeneration.

We are living longer than at any point time in human history. ${ }^{1}$ Life expectancy has increased in the developed world from an average 40.2 years in 1891 to 82.8 years in 2018 (for females in United Kingdom ${ }^{2}$ ).

At the beginning of the 20th century, the epidemiological transition that led to more than a doubling in the average lifespan sparked the idea that ever-increasing age and near immortality could be reached if the human being was provided with appropriate nutrition and correct health interventions (e.g., child immunization). ${ }^{3}$

It was in this context, in an era of rapid change, when the controversial Nobel Prize laureate and eugenicist Alexis Carrel propelled this idea of immortality. ${ }^{4}$ In his experiments, Carrel, who was attempting to preserve life outside the body, claimed to have maintained cells from chick heart embryos alive and dividing from 1912 to $1946 .{ }^{5,6}$ The implicit idea of these studies was that by understanding cellular mechanisms, the secrets of an organism's immortality could be revealed. ${ }^{7}$

This concept was challenged when Hayflick and Moorhead described that human cells in culture showed a limited proliferative capacity and entered cellular senescence. ${ }^{8}$ Hayflick and Moorhead observed how the cells adapted to the culture conditions and began to proliferate but, after certain number of divisions, they invariably changed their morphology, remaining metabolically active but unable to divide again (despite the presence of growth factors in the medium). ${ }^{8}$

published online February 9, 2021
DOI https://doi.org/ $10.1055 / \mathrm{s}-0040-1722262$ ISSN 0272-8087.
Hayflick termed this phenomenon cellular senescence, and despite the initial reluctance of his colleagues to accept that primary cell cultures were mortal, ${ }^{6}$ subsequent publications helped define a new phenotype, the function of which continues to be unraveled.

\section{Cellular Senescence in Homeostasis and Disease}

Our cells and tissues are constantly exposed to injury, including the liver, subjected to injury due to its role in toxin metabolism and susceptibility to infections. ${ }^{9}$

In response to a variety of stresses, cells either undergo apoptosis (a form of programed death) or senescence. ${ }^{10} \mathrm{Al}$ though each mechanism has its own advantages, in a context where a cell becomes mutated, senescence protects the integrity of the tissue by preventing proliferation of these cells and the transmission of destructive alterations to the next generation that may give rise to further injury or cancer. ${ }^{11}$

Senescence is therefore considered a preventive mechanism against tumor formation. This is supported by the fact that tumorigenesis selects cells that can bypass senescence $^{12,13}$ and that alterations of key effectors of senescence, such as p53, are common in tumors. ${ }^{14}$

When one of these cells acquires a senescent phenotype, it is no longer able to proliferate, but remains metabolically

(C) 2021. The Author(s).

This is an open access article published by Thieme under the terms of the Creative Commons Attribution License, permitting unrestricted use, distribution, and reproduction so long as the original work is properly cited. (https://creativecommons.org/licenses/by/4.0/)

Thieme Medical Publishers, Inc., 333 Seventh Avenue, 18th Floor, New York, NY 10001, USA 
active and is able to communicate with the surrounding environment. ${ }^{11}$ To do so, senescent cells secrete a myriad of factors that act in an autocrine and paracrine manner to reinforce senescence, communicate its compromised status to the rest of the tissue, and to activate immune surveillance to promote clearance of the damaged area and induce regeneration. ${ }^{15}$ It is therefore an essential mechanism activated during tissue damage, wound healing, ${ }^{16}$ tissue plasticity, and regeneration. ${ }^{17,18}$

In line with this protective role, senescence can be activated in postmitotic nonmalignant cells that if uncontrolled could aggravate certain pathologies. For example, cellular senescence of scar-forming cells attenuates fibrosis in the liver, ${ }^{19,20}$ kidney, ${ }^{21}$ heart, ${ }^{22}$ and skin, ${ }^{16,23}$ restraining uncontrolled scarring and providing a regenerative environment.

Senescence is also part of a normal physiological response in adults. Normal megakaryocytes, ${ }^{24}$ natural killer (NK) cells at the interface between fetus and mother ${ }^{25}$ and the syncytiotrophoblast at the placenta, ${ }^{26}$ undergo senescence as part of their normal maturation. Senescence is essential for the correct functioning of these systems and might provide protective mechanisms later in life. ${ }^{26}$

Senescence has also been described to fine-tune embryo development, promoting a correct balance between cell populations during embryo patterning as well as eliminating transient developmental structures. ${ }^{27,28}$

As an antitumoral, proregenerative, homeostatic, and developmental mechanism, senescence shows its positive physiological sides. However, senescence is a highly complex and plastic phenotype that can exert antagonistic effects depending on the context.

For example, senescent cells contribute to persistent chronic inflammation ("inflammaging") 29,30 as well as drive tumorigenesis by promoting angiogenesis and cell motility (i.e., invasion, migration, and metastasis). ${ }^{31}$ Furthermore, chronic senescence and a maintained senescence-associated secretory phenotype (SASP) have been shown to actively contribute to several pathological conditions such as atherosclerosis, ${ }^{32}$ diabetes, ${ }^{33}$ osteoarthritis, ${ }^{34}$ obesity, ${ }^{35}$ and neurodegenerative diseases. ${ }^{36}$ The list of conditions in which senescence negatively contributes to the development of the disease continues to increase, and for many conditions its role still needs to be clarified.

Cellular senescence is also one of the main hallmarks of aging. ${ }^{37}$ Senescent cells appear to increase in number in a variety of aged mammalian tissues, ${ }^{38-42}$ either due to the accumulation of potentially deleterious mutations or due to the decline in senescence-clearing mechanisms with age. $^{30,43}$ This persistence leads to local and systemic inflammation, procarcinogenic effects, and the emergence of a pernicious microenvironment that promotes further injury. $^{15,43}$

In summary, senescence is capable of exerting both detrimental and beneficial processes. This seemingly antagonistic pleiotropy might be partially explained by the fact that the interaction of the senescent cells with their microenvironment is highly dependent on the context (i.e., stress inductors, cell type, rapid vs. persistent). In general, a transient response (in which the senescent cells are rapidly cleared) promotes tissue regeneration, whereas persistent senescence can have devastating effects for the organism.

\section{Features of Cellular Senescence: An Overview}

Senescence is a highly heterogeneous response that spatially and temporally depends on the context (inductor, duration of stimulus, cell type, etc.). This heterogeneity explains the lack of a universal biomarker, forcing researchers in the field to identify several traits to asseverate the presence of senescence. Recently, the International Cell Senescence Association proposed a consensus of markers to help define this phenotype including cell-cycle arrest, macromolecular damage, deregulated metabolism, and SASP. ${ }^{11}$ It is important to understand that not all of these characteristics need to be present, but a combination is required to determine the presence of senescence ${ }^{11,15}$ (- Fig. 1).

The hallmark of senescence is an irreversible cell-cycle withdrawal instigated by stressful insults including aberrant proliferation. ${ }^{11,43}$ Two families of cyclin-dependent kinases (CDK) inhibitors are in charge of maintaining this proliferative arrest: INK4 family (comprising p16 ${ }^{\mathrm{INK} 4 \mathrm{~A}}$ [CDKN2A], $\mathrm{p} 15^{\mathrm{INK} 4 \mathrm{~B}}, \mathrm{p} 18^{\mathrm{INK} 4 \mathrm{C}}$, and $\mathrm{p} 19 \mathrm{ARF}^{\mathrm{INK} 4 \mathrm{D}}$ ) and Cip/Kip family (including $\mathrm{p} 27^{\mathrm{Kip} 1}, \mathrm{p} 57^{\mathrm{Kip} 2}$, and $\mathrm{p} 21^{\text {WAF1/Cip1 }}$ [CDKN1A] which is regulated by $\mathrm{p} 53$ ). These factors inhibit the activity of CDKs by maintaining the retinoblastoma (RB) family members in their hypophosphorylated form, complexed to E2F family transcription factors. RB-dependent repression of E2F activity results in cell-cycle arrest, which cannot be reversed by inactivation of $\mathrm{RB}$ or $\mathrm{p} 53 .^{44,45}$ This irreversible arrest is also associated with an active blockage of apoptosis mediated by antiapoptotic BCL-2 family members. ${ }^{46}$

Given that senescence is a result of stressful insults, it is not surprising that DNA damage response (DDR) markers characterize its phenotype. DDR is an evolutionary conserved pathway that senses DNA damage, amplifies its signal, and engages with the cell cycle through senescence effectors. ${ }^{47,48}$ It can be assessed by cumulative activation of the double-strand break sensor proteins $\gamma \mathrm{H} 2 \mathrm{~A} . \mathrm{X}, 53 \mathrm{BP} 1, \mathrm{CHK} 2$, and MDC1. When the damage persists, these DDR foci become permanent generating DNA-SCARS, DNA segments with stable chromatin alterations characterized by the presence of single-stranded DNA, and lack of DNA-repair proteins (RPA, RAD51). ${ }^{48-51}$

Senescence is also associated with chromatin changes including senescence-associated heterochromatin foci (SAHF, facultative heterochromatin domains that contribute to silencing of proproliferative genes ${ }^{52,53}$ visualized as DAPIdense foci ${ }^{54}$ ) and senescence-associated distension of satellites (SADS, where centromeres' DNA unraveled from its compact state preceding SAHF's formation ${ }^{55}$ ). Other common signs of DDR in senescence include oncogene activation/loss of tumor suppressors, ${ }^{56}$ presence of micronuclei/nucleoplasmic bridges or nuclear buds, 57,58 and loss of Lamin B1 (a component of the nuclear lamina 


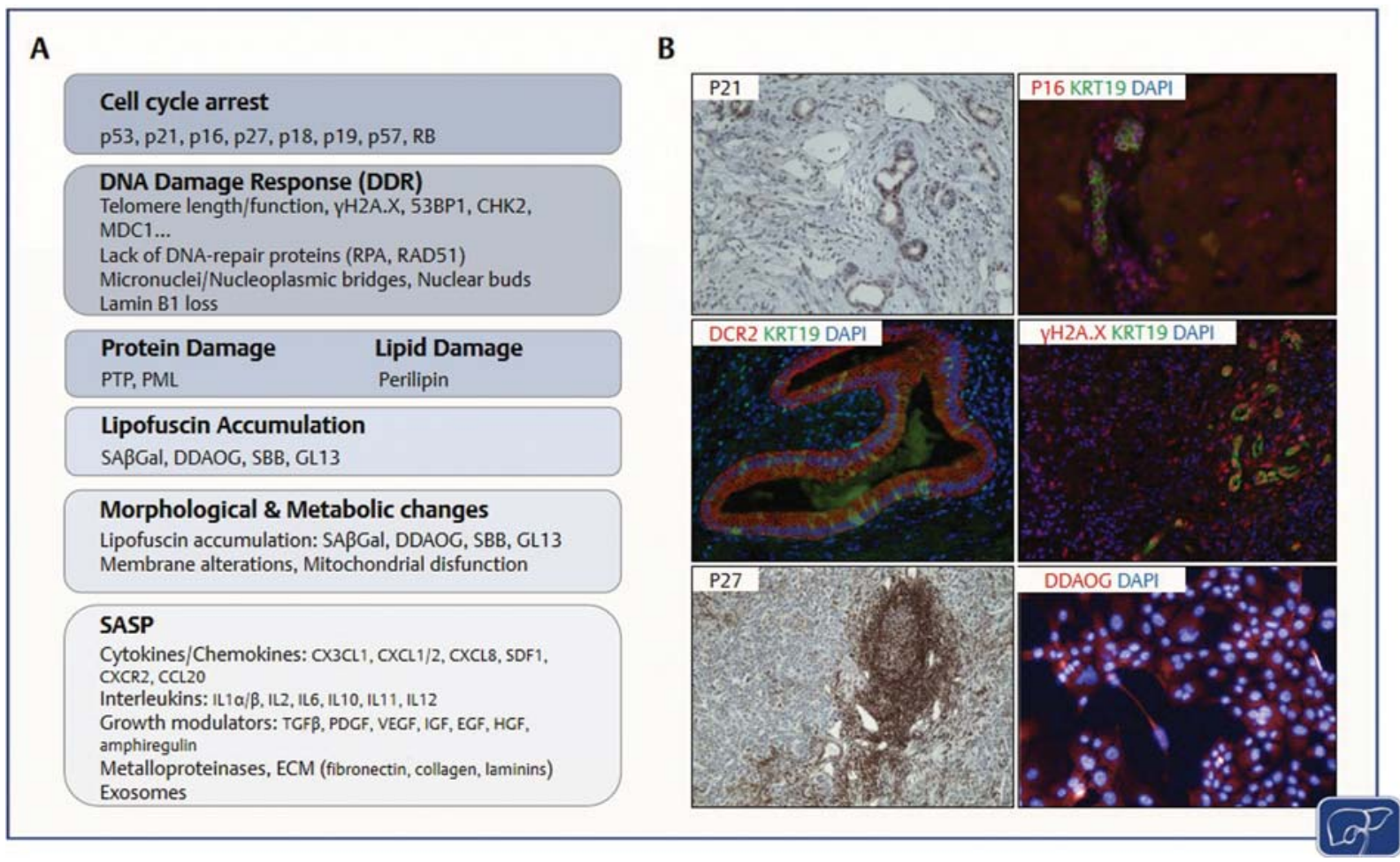

Fig. 1 Hallmarks of senescence in liver disease. (A) Hallmarks of senescence, including cell-cycle arrest, ${ }^{11,42} \mathrm{DDR},{ }^{55,56}$ protein and lipid damage, lipofuscin accumulation, ${ }^{37,72-75}$ morphological and metabolic changes, ${ }^{83}$ and production of senescence-associated secretory phenotype (SASP). ${ }^{15,30,90}$ (B) Markers of senescence in liver disease. The images represent immunohistochemistry or immunofluorescence of: P21 in primary biliary cholangitis (PBC); P16 (red) in keratin 19-positve cholangiocytes (KRT19, green) in chronic rejection; decoy receptor 2 (DCR2, green) in Krt19-positive cholangiocytes (red) in PBC; үH2A.X (red) in KRT19-positive cholangiocytes (green) in PBC; P27 in primary sclerosing cholangitis (PSC); DDAOG showing lipofuscin accumulation of mouse cholangiocytes treated with TGF $\beta$ for 24 hours. All images were taken at 20 or $40 \times$. DAPI is shown in blue. DDR, DNA damage response.

which triggers both local and global modifications in chromatin methylation and correlate with SAHF and $\operatorname{SADS}^{59,60}$ ).

Telomere erosion (the progressive shortening of the specialized nucleoprotein structures that protect chromosome ends) has been shown to induce and stabilize senescence while contributing to a persistent DDR response. ${ }^{61-65}$ Therefore, length shortening and presence of telomere-associated foci (TAFs, where markers of DNA damage such as $\gamma \mathrm{H} 2 \mathrm{~A} . \mathrm{X}$ colocalize with telomeres ${ }^{66}$ ) are frequently used as senescence biomarkers.

Damage also impacts at the protein level where the lysosomal content increases and aggregates, forming oxidized complexes known as lipofuscin. ${ }^{38,67}$ Lipofuscin accumulation can be detected by using SABGal, ${ }^{38}$ far-red fluorescence probes such as DDAOG, ${ }^{68,69}$ Sudan Black B (SBB) staining ${ }^{70}$, or SBB analogues such as GL13. ${ }^{71}$ Other types of protein damage include protein tyrosine phosphatases (PTPs ${ }^{72,73}$; detected by monoclonal antibodies that recognize oxidized cysteine ${ }^{74}$ ) and protein carbonyl residues resulting from protein carbonylation by reactive oxygen species (ROS) ${ }^{75}$ Finally, as protein damage is not reversible, activation of the ubiquitin proteasome system ${ }^{73,76}$ and presence of PML (which act as ROS sensors ${ }^{77}$ ) can also be useful to assess senescence.

Senescent cells also display morphological changes becoming larger, flatter, increasing lysosomal content, ${ }^{78}$ and the cytoplasm and nucleus appear vacuolised, ${ }^{79,80}$ although this is difficult to assess and less obvious in vivo due to the architectural support of the tissue. Changes in the plasma membrane are likely representative of the lipid damage that occurs in senescent cells (such as lipid-derived aldehyde modifications ${ }^{81}$ or lipid accumulation that can be detected using immunostaining for lipid-associated proteins such as perilipin $^{82}$ ).

Furthermore, senescent cells show an abnormal metabolic profile, and, although they remain metabolically active, display mitochondrial dysfunction with more abundant mitochondria, decreased membrane potential, increased mass, and abundance of tricarboxylic acid-cycle metabolites. ${ }^{83}$ They also have compromised ATP production and produce more ROS, ${ }^{84}$ potentiating the senescence effects. ${ }^{85}$ However, as metabolic changes are a commonality with other cellular processes, it is not a consistent marker of senescence.

Finally, senescent cells secrete a variable set of factors termed the Senescence-Associated Secretory Phenotype (SASP) responsible for the beneficial and deleterious effects of senescence within the tissue. ${ }^{15,86-88}$

The SASP comprises a highly dynamic network ${ }^{89}$ of cytokines and chemokines (CX3CL1, CXCL1/2, CXCL8, SDF1, CXCR2, CCL20), interleukins (IL1 $\alpha / \beta$, IL2, IL6, IL10, IL11, IL12), angiogenic factors and growth modulators (TGF $\beta$, PDGF, VEGF, IGF, EGF, HGF, amphiregulin), metalloproteinases (MMP), extracellular matrix (ECM; fibronectin, collagen, laminins), and exosomes. ${ }^{90,91}$ These factors allow the 
senescent cell to communicate its compromised state, reinforcing cell-cycle arrest in an autocrine manner (therefore avoiding a potential bypass toward carcinogenesis ${ }^{86,87}$ ), spreading senescence to sensitize neighboring cells to the presence of stressful stimulus, and engaging the innate immune system for clearance of senescent cells. ${ }^{92-94}$

\section{Cellular Senescence in the Liver}

The liver's roles in the metabolism of toxins and its susceptibility to infectious agents make it prone to injury. In this context, senescence may be a mechanism to contain damage and promote regeneration. Whether senescence represents a consequence of the damage, an inductor agent, or an intermediate stage of disease remains unclear; however, it is a common factor across etiologies. Here we disclose the empirical evidence of senescence in the different cell populations of the liver, with particular focus on potential markers. By doing so, we would like to provide a comprehensive view of senescence and its consequences in the context of liver homeostasis, disease, and regeneration (see -Table 1 and - Fig. 2).

\section{Cholangiocytes and Cellular Senescence}

The first description of cellular senescence in bile ducts comes from Lunz and collaborators, who identified senescent cholangiocytes in early stages of chronic liver allograft rejection (CR) and obstructive cholangiopathies..$^{95} \mathrm{CR}$ in liver transplant recipients is characterized by cytological alterations in cholangiocytes and ductopenia (disappearance and obliterative arteriopathy of bile ducts) resulting in progressive jaundice, allograft dysfunction, and ultimately a second transplant. Lunz et al demonstrated that ductopenia is preceded by a period of cellular senescence (characterized by p21-positive cholangiocytes that presented shortened telomeres). ${ }^{95}$ Sasaki and colleagues described similar findings ${ }^{96}$ and Brain et al demonstrated a positive correlation between the number of senescent cholangiocytes and an increasing grade of acute rejection, biliary anastomotic obstruction, and stricturing. ${ }^{97}$

Furthermore, Lunz et al show that cyclosporine treatment (an immunosuppressant used at liver transplantation) induces senescence in a TGF $\beta$-dependent manner, potentially aggravating the progression of the cholangiocellular damage rather than contributing to a successful engraftment. ${ }^{95}$ Interestingly, Demirci and colleagues showed increased TGFB1 in macrophages localizing in close proximity to the portal tracts of liver allografts with $\mathrm{CR},{ }^{98}$ potentially suggesting that communications between macrophages and cholangiocytes might result in TGF $\beta 1$-dependent induction of senescence in the later population.

Senescence is present in the cholangiocytes of pediatric patients with varying etiologies, ${ }^{99,100}$ which might indicate pathological development not associated with aging. In disorders that affect cholangiocytes such as biliary atresia, ${ }^{99,100}$ senescence can be observed in hepatocytes. Conversely, in conditions that primarily affect hepatocytes (e.g., tyrosinemia and fulminant hepatitis ${ }^{99}$ ), senescence can be observed in both hepatocytes and cholangiocytes, suggesting transference of senescence between liver populations although potential effects of these mechanisms have to be clarified.

Senescence has also been shown to play a critical role in the development of primary sclerosing cholangitis (PSC), an autoinflammatory disorder characterized by fibrosis, stricturing, and obliteration of bile ducts. ${ }^{101}$ Cholangiocytes in PSC show multiple senescent markers such as SABGal, p21, p16, үH2A.X, p27, and DCR2. ${ }^{96,102,103}$

PSC's cholangiocytes are characterized by N-Ras-induced senescence, ${ }^{102}$ reduction of Bmi1 (a repressor of p16), ${ }^{104}$ and a complex SASP (i.e., IL1 $\alpha$, IL6, IL8, TGF $\beta$ chemokine ligand 1 , CCL2, and PAI-1 secretion). ${ }^{102,103}$ Components of the SASP has been shown to aggravate the progression of the disease by increasing fibrosis, activating immune surveillance (attracting macrophages both in vitro ${ }^{105}$ and in vivo ${ }^{103}$ ), and inducing secondary senescence in the hepatic parenchyma by means of $\mathrm{N}$-Ras activation ${ }^{102}$ and TGF $\beta$-dependent mechanisms. ${ }^{103}$ Moreover, pharmacological abrogation of these pathways inhibited senescence, highlighting the potential for new therapeutic interventions toward PSC treatment in the context of cellular senescence. ${ }^{102,103}$

Suggested mechanisms of senescence in PSC include regulation by the transcription factor ETS1 and p300 which promotes cholangiocyte resistance to apoptosis by inducing BCL-XL expression. ${ }^{106,107}$ In fact, pharmacological inhibition of BCL-XL with the small-molecule inhibitor A1331852 selectively kills senescent cholangiocytes in the Mdr2 (Abcb4) - /- murine model of PSC, ${ }^{108}$ reducing liver fibrosis by means of a PDGF-mediated apoptotic priming of mesenchymal cells. ${ }^{106}$

The absence of intestinal microbiota exacerbates biliary senescence in the same PSC murine model and ursodeoxycholic acid (an antioxidant metabolite produced by commensal microbiota ${ }^{109}$ ) is able to abrogate senescence in vitro ${ }^{110}$ providing an interesting link between microbiota, senescence, and the progression of biliary disease.

Another potential mechanism is derived from the knockout of secretin receptor (SR, which plays a crucial role in the regulation of biliary damage and fibrosis) in a PSC murine model, effectively reducing the levels of senescence and associated ductular reaction and fibrosis. ${ }^{111}$

In a similar fashion, senescence is present in the bile ducts in primary biliary cholangitis (PBC), an autoimmune condition characterized by granulomatous destruction of bile ducts slowly progressing to fibrosis, cirrhosis, and liver failure. ${ }^{112}$

PBC cholangiocytes exhibit senescence markers such as SABGal, p16, p21, significantly shorter telomeres, and $\gamma \mathrm{H} 2 \mathrm{~A}$. $X$ foci indicative of DNA damage. ${ }^{96,113-115}$ Interestingly, p21 expression in some cholangiocytes appears to be independent of $\mathrm{p} 53$, suggesting the presence of secondary paracrine senescence mechanisms. This cholangiocyte's SASP might be able to modulate the microenvironment by upregulating the expression of various chemokines such as CCL2 and CX3CL1 ${ }^{116,117}$, promoting the infiltration of inflammatory CX3CR1+ CD3positive $\mathrm{T}$ cells ${ }^{117}$ and $\mathrm{F} 4 / 80+$ macrophages. ${ }^{103}$ Furthermore, 


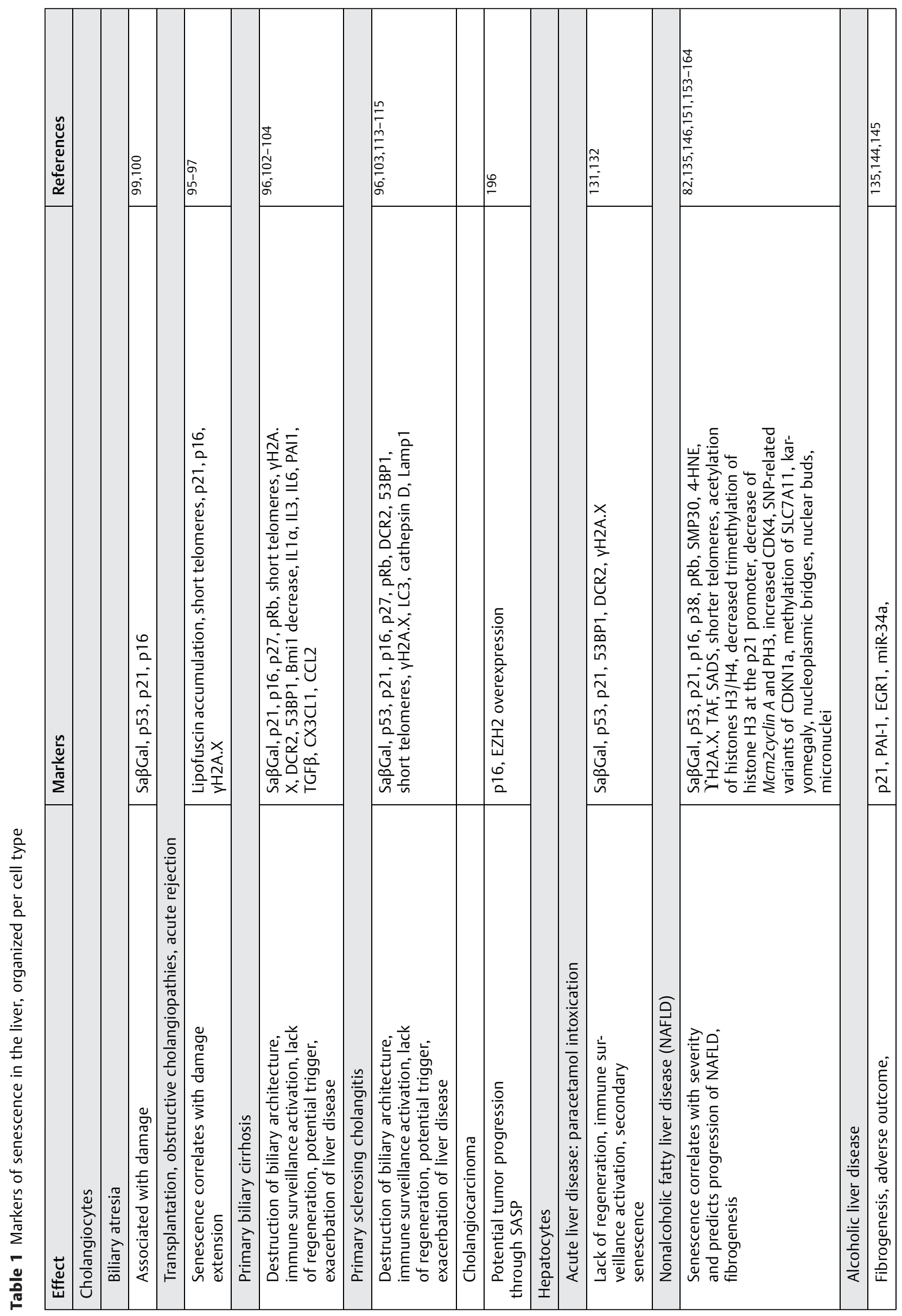




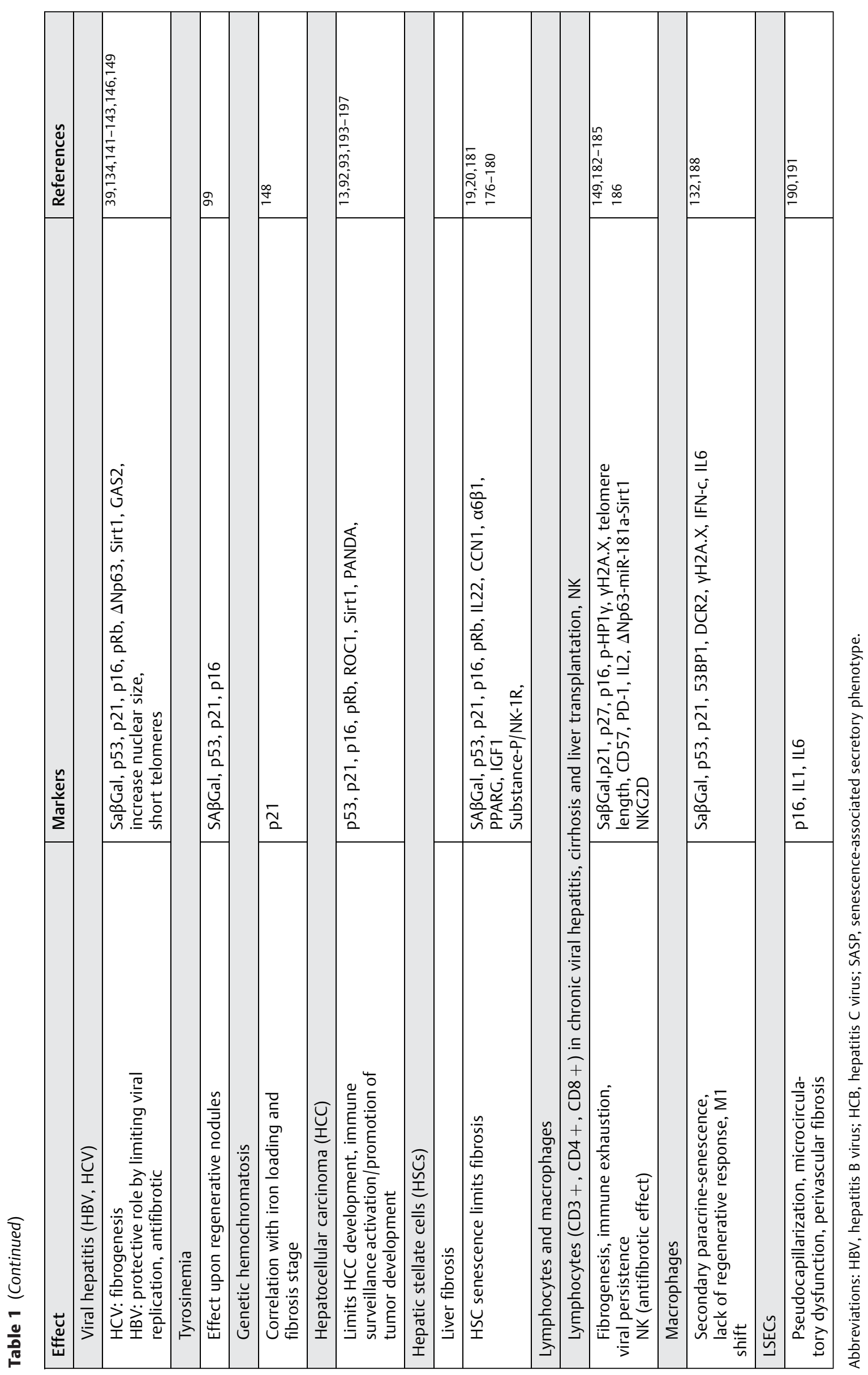




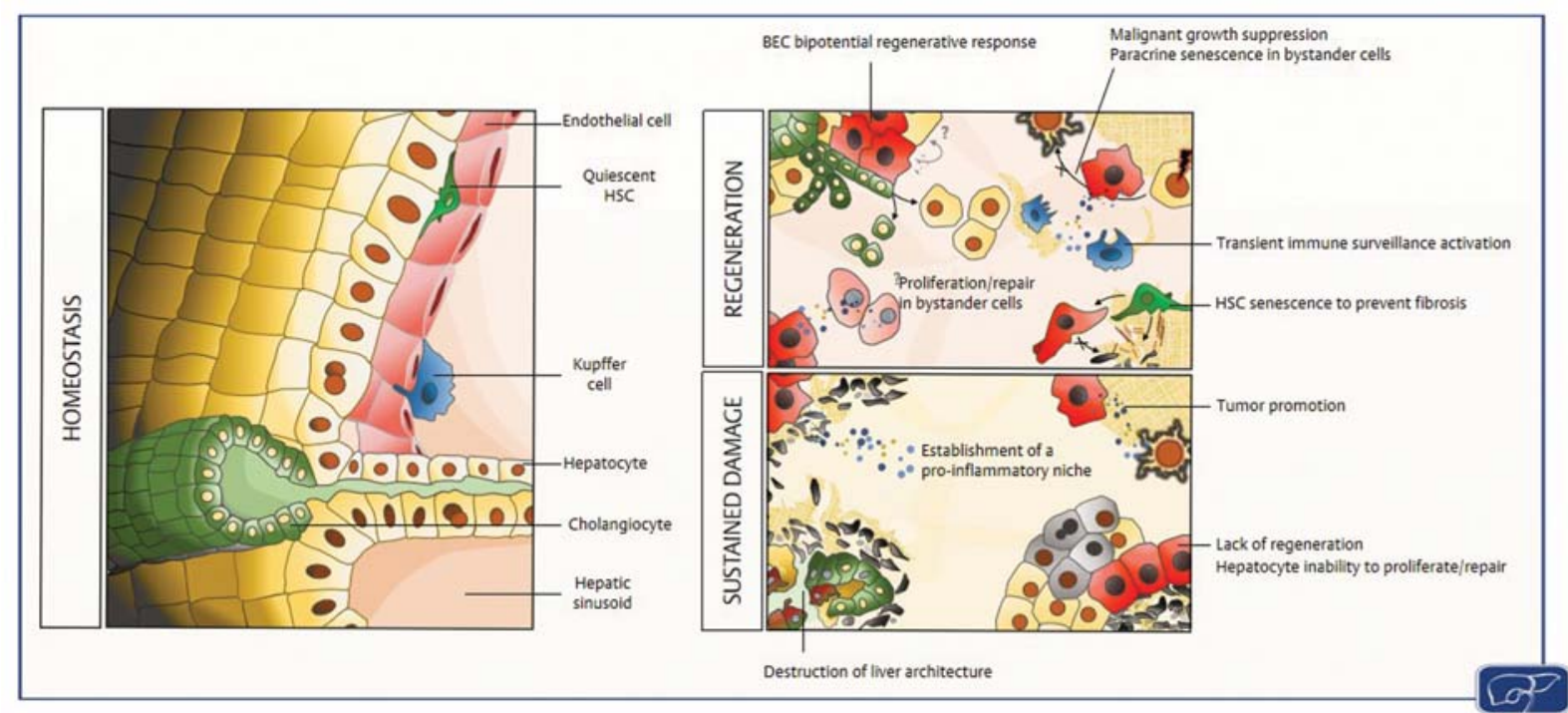

Fig. 2 Effects of cellular senescence in the liver. Left image depicts a normal liver and its populations. There are no known effects of cellular senescence during homeostasis or liver development. Right upper quadrant: beneficial effects of senescence might be associated with an antifibrotic and proregenerative response. Clockwise: senescent cells might induce BEC-bipotential response during liver disease to replace injured cells and promote regeneration and repair. ${ }^{198}$ Damaged cells are able to engage senescent programs to avoid unwanted proliferation and tumor progression. Moreover, they are able to induce senescence in neighboring cells to expand the senescent fingerprint and to alert of the damaging agent. ${ }^{7,42}$ Senescent cells elicit a transient immune response that eliminates the damaged cells, promoting regeneration. ${ }^{15,30}$ Senescence in activated HSC prevents fibrogenesis, avoiding further scarring and cirrhosis progression. ${ }^{19}$ SASP might also be responsible of inducing proliferation of neighboring cells to promote regeneration and repair. The lower image represents some of the known detrimental effects of senescence at the molecular level. Clockwise, SASP establishes a proinflammatory niche that exacerbates injury. ${ }^{11,30,90}$ Senescent cells promote tumorigenesis. ${ }^{30,46}$ Expansion of the senescent fingerprint to the surrounding cells reduces the regenerative capacity of the tissue. ${ }^{105}$ Senescence alters the microenvironment and promotes destruction of the liver architecture, as seen in the bile ducts of PBC and PSC patients. ${ }^{105}$ BEC, biliary epithelial cell, HSC, hepatic stellate cell; PBC, primary biliary cholangitis; PSC, primary sclerosing cholangitis; SASP, senescence-associated secretory phenotype.

monocytes/macrophages, neutrophils, and plasma cells expressing markers of autophagy such as LC3 and PDC-E2 (pyruvate-dehydrogenase complex-E2, the immunodominant autoantigen of $\mathrm{PBC}$ ) are found in close proximity to the damaged bile ducts in PBC. ${ }^{118,119}$

These findings highlighted a potential connection in $\mathrm{PBC}$ for senescence and autophagy (critical for the rapid protein remodeling required for the transition from proliferation to senescence ${ }^{120}$ ). Indeed, PBC cholangiocytes show markers of autophagy including p62 aggregation (p62 sequestosome-1), ${ }^{121}$ LC3, LAMP-1, and cathepsin D. ${ }^{122}$ In fact, LC3 colocalizes with the mitochondrial proteins PDC-E2 and CCO, ${ }^{118}$ and inhibition of autophagy by means of 3-methyladenine significantly suppressed cellular senescence in cultured cells reducing the levels of CCL2 and CX3CL1. ${ }^{122}$

Together these data suggest a role for senescence in the modulation of cholangiocellular damage and indicate that targeting senescence can potentially improve the conditions and the secondary symptoms associated with the progression of biliary disease. However, the mechanisms underlying these phenomena and their contribution to the onset/development of biliary disease remain unclear. Given that the K19Cre ${ }^{\mathrm{ERT} 2} \mathrm{Mdm} 2$ - /- murine model (able to induce senescence exclusively in cholangiocytes) recapitulates numerous characteristics of PBC/PSC, ${ }^{103}$ we suggest that senescence might be an inducer rather than a consequence of biliary disease. However, the mechanisms leading to this first generation of senescence are yet not clarified.

Oxidative stress (a known inductor of cellular senescence $)^{123,124}$ is characteristic of biliary pathology. ${ }^{124,125}$ The alterations in vascular supply associated with some of these conditions are an important source of oxidative stress ${ }^{126}$ and immune infiltrates contribute to biliary damage through the production of ROS and nitric oxide. ${ }^{96}$ In fact, multiple in vitro experiments demonstrated that oxidative stress consistently induces senescence in cholangiocytes. ${ }^{96,97,102}$ However, multiple other mechanisms including DNA damage or serum deprivation are equally capable of inducing senescence in cholangiocytes, highlighting that induction is multifactorial and likely impacts various biological processes. ${ }^{96,97}$

Telomere shortening has also been described as an inductor of senescence in biliary disease, with short telomeres being characteristic of PBC cholangiocytes. ${ }^{114}$ However, given that in this study PBC and control liver samples had a similar age ratio, senescence in this context is unlikely to be related to aging, but rather could be a direct consequence of DNA damage.

Autophagy and immunological damage have also been proposed as inductors and/or contributors of cholangiocyte senescence. ${ }^{118,121}$ The SASP is certainly able to induce further damage as well as senescence in bystander cholangiocytes and other liver populations, ${ }^{102,103}$ suggesting that once that senescence is established it might exert further detrimental effects via a positive feedback loop. 
Finally, the potential contribution of other insults (i.e., toxic bile accumulation during flow impairment, immune response, portal inflammation, and ECM deposition) to cholangiocellular senescence is worth noting. In summary, there is a complex picture for senescence in biliary pathology that requires further investigation.

\section{Hepatocytes and Cellular Senescence}

The hepatocyte changes with age. ${ }^{127}$ Hepatocytes decline in volume $^{128}$ and the nucleus changes morphology while increasing the incidence of polyploidy. ${ }^{127,129}$ Although hepatocytes accumulate markers of senescence in later stages of life, ${ }^{129}$ they are not particularly susceptible to the implementation of senescence in homeostasis ${ }^{130}$ (probably reflecting their high regenerative and restorative capacities). However, senescent hepatocytes are common in a variety of pathologies, indicating that this might be a relevant mechanism in the context of liver disease.

Hepatocyte senescence is strongly induced in the setting of severe acute liver injury. ${ }^{131,132}$ Hepatocytes in paracetamol poisoning are characterized by the presence of SABGal, p21, and $\gamma \mathrm{H} 2 \mathrm{~A} . \mathrm{X}$, and senescence is able to spread between adjacent cells in a feedback loop dependent on macrophages' TGF $\beta 1$ secretion. ${ }^{132}$ This mechanism might initially help to contain the pericentral necrosis seen in paracetamol-derived injury, as the senescent cells seem to surround the damaged areas. However, it actively contributes to the lack of regeneration seen in acute liver injury, ${ }^{132}$ highlighting the potential of targeting senescence and its effectors to restore the regenerative response of the liver.

Similarly, senescent hepatocytes are characteristic of chronic liver disease, a condition caused by sustained liver damage, accumulation of scarring tissue (fibrosis), and eventual progression to cirrhosis manifesting as a deterioration of liver function. In this case, the hepatocyte's telomere length inversely correlates with increasing levels of cirrhosis ${ }^{39,133-135}$ and mutations in telomerase genes TERT and TERC are risk factors for the development of cirrhosis. ${ }^{136,137}$ In fact, murine models in which senescence is induced in hepatocytes through a telomerase knockout show increased fibrosis, accelerated onset of cirrhosis, and reduced survival. ${ }^{138,139}$ Moreover, mice that exhibit a deficient senescent response (e.g., p21 knockout) display reduced $\mathrm{CCl} 4$-induced fibrosis ${ }^{140}$ indicating the ability of senescent cells to regulate their microenvironment through the control of ECM deposition and production of profibrotic factors.

Etiologies where presence of senescent hepatocytes have been reported include viral hepatitis $B$ and $C$ virus (HBV and HCV), ${ }^{39,141-143}$ alcoholic liver disease (ALD), ${ }^{135,144,145}$ nonalcoholic fatty liver disease (NAFLD ${ }^{146,147}$ ), and genetic hemochromatosis. ${ }^{148}$

HBV and HCV exhibit large cellular changes in hepatocytes identified as senescent lesions (with accumulation of $\mathrm{p} 21$, SAßGal, and SAHF with me-H3K9 ${ }^{134}$ ).

In HBV, hepatocytes are found in a p21-mediated G1 arrest, showing decreased markers of late stages of cell-cycle progression, a decrease of telomere length, and an increase of nuclear size, all indicative of a strong senescent response. ${ }^{143}$ Interestingly, the core antigen of $\mathrm{HBV}(\mathrm{HBcAg})$ can only be observed in actively proliferating hepatocytes with intact telomere length. Moreover, p21 is associated with limitation of fibrosis and cell-cycle entry (assessed by Mcm2 expression) and correlates with increased levels of fibrosis and viral replication. ${ }^{143}$ These results appear to confer senescence a protective role as HBV is confined in young, proliferative hepatocytes, potentially explaining the low viral load in cirrhotic patients with a large number of senescent hepatocytes. $^{146}$

Senescence is characteristic of hepatocytes in HCV (with elevated expression of p21, upregulation of Trp53 and CDKN2A, ${ }^{141}$ SABGal accumulation, ${ }^{39}$ presence of 8 -OHdG [a marker of oxidative DNA damage], ${ }^{142}$ and a decrease of telomere length, ${ }^{39,142}$ among others). In this context, Sekoguchi et al proposed that senescence may be a consequence of an HCV-dependent hyperproliferative response that induces telomere shortening and increases fibrosis. ${ }^{142}$ However, Wandrer et al proposed that immune CD3 $+\mathrm{T}$ cells, rather than hepatocytes, are the predominant senescent population in HCV during fibrosis progression. ${ }^{149}$ This finding opens new avenues for the selective targeting of different liver populations by inducing host senescence to avoid viral replication or inhibiting immune senescence to contain the infection.

In ALD, the presence of senescent p21-positve hepatocytes is closely related to fibrosis development and an adverse outcome. $^{144,150}$ In fact, 5 weeks of ethanol feeding in mice leads to $S A \beta G a l$ accumulation and upregulation of senescence initiators (PAI-1 and EGR1) in hepatocytes. ${ }^{145}$ Interestingly, silencing of either PAI-1 or EGR1 reduces senescence in human-cultured hepatocytes while decreasing levels of profibrotic markers, ${ }^{145}$ suggesting a direct link between the onset of senescence and ALD progression. Similarly, inhibition of miR-34a (which is found increased in clinical samples of $A L D^{144}$ ) decreases overall hepatocyte senescence in ethanolfed mice while ameliorating fibrosis. ${ }^{144}$ Altogether these results suggest a potential role for cellular senescence as a causal event of an effector of ALD progression.

NAFLD and its histological phenotype nonalcoholic steatohepatitis (NASH) encompass a spectrum of conditions, of a broad range of etiologies, characterized by the accumulation of hepatic steatosis in patients who do not consume harmful amounts of alcohol.

NAFLD hepatocytes are characterized by the presence of multiple senescence markers including p53, ${ }^{151}$ SA 3 Gal, p21,

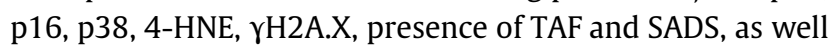
as karyomegaly as assessed by morphometric analysis of DAPI. ${ }^{82,135,152}$ As with other chronic liver diseases, hepatocyte senescence correlates with severity of NAFLD. $82,135,153$ Hepatocyte in NAFLD have shorter telomeres, ${ }^{135,154,155}$ increased levels of $\mathrm{CDK} 4,{ }^{156}$ and a significant decrease of $\mathrm{Mcm} 2$, cyclin A, and PH3, all indicative of lack of cell-cycle progression beyond the $\mathrm{G} 1 / \mathrm{S}$ phase. ${ }^{133}$ Single-nucleotide polymorphism-related variants of CDKN1A (p21), ${ }^{157}$ acetylation of histones $\mathrm{H} 3$ and $\mathrm{H} 4$, and decreased trimethylation of 
histone $\mathrm{H} 3$ at the $\mathrm{p} 21$ promoter $^{152}$ directly correlate with NAFLD progression.

Further markers of senescence, such as genomic instability (assessed by nucleoplasmic bridges, nuclear buds, and micronuclei $)^{158}$ and DNA damage, ${ }^{159}$ are also directly related to NAFLD progression. Furthermore, DNA methylation appears to be characteristic of NAFLD, ${ }^{160}$ with upregulation of genes associated with lipid metabolism and downregulation of genes related to proliferation and transcriptional regulation, ${ }^{161}$ methylation of SLC7A11 indicative of reduced steatotic risk, ${ }^{162}$ and hypomethylated genes characterizing advanced stages of NAFLD ${ }^{163}$ and changes in nuclear size. ${ }^{82,164}$

Several senescence-related mechanisms have been causally related to NAFLD onset/progression. For example, as the CDK4-C/EBP $\alpha-p 300$ axis is a critical regulator of NAFLD, pharmacological inhibition of CDK4 results in cellular senescence ablation and reversion of age-dependent steatosis. ${ }^{156}$ The reduction of hepatic senescent protein SMP30 (regucalcin, an antioxidant protein that plays an important role in intracellular $\mathrm{Ca}^{2+}$ homeostasis and oxidative stress ${ }^{165}$ ) has been associated with NAFLD progression and fibrosis in a stage-dependent manner. ${ }^{166}$ Consistently, SMP30 knockout mouse develops characteristics of fatty liver disease, ${ }^{167-169}$ suggesting a direct role for SMP30 deregulation in the development of NAFLD.

Finally, conditional induction of senescence in hepatocytes (using the Alb-Xpg-/- mice that accumulates DDR markers and accelerates karyomegaly in hepatocytes ${ }^{170}$ ) impairs the capacity of mitochondria to oxidize fatty acids, thus accumulating fat in the hepatic parenchyma. ${ }^{82}$ Interestingly, elimination of senescent cells using suicide genemediated ablation (INK-ATTAC mice), a combination of senolytics (dasatinib + quercetin $^{82}$ ), or caloric restriction ${ }^{171}$ protects or even reverses hepatic lipid accumulation, ${ }^{82}$ suggesting new therapeutic approaches based on targeting senescence.

As with cholangiocytes' senescence, consistent and marked oxidative injury appears to play a crucial role in the establishment of hepatocellular senescence.

Oxidative stress is a common element of chronic liver disease, contributing to the onset and progression of inflammation and fibrosis. ${ }^{172}$ For example, patients with NAFLD show a high level of oxidative stress ${ }^{173,174}$ that contribute to fat accumulation, telomere shortening, and DNA damage in hepatocytes. ${ }^{146}$ Senescence also contributes to fat accumulation when mitochondria lose their ability to metabolize fatty acids efficiently. ${ }^{82}$ Therefore, either as a cause or a consequence of the pathology, senescence appears to generate a continuous feedback loop that negatively impacts the hepatocyte and its mitochondrial function. Another example: HCV core protein is able to directly induce oxidative injury and mitochondrial damage. ${ }^{175}$ In a similar fashion, telomere attrition and telomerase mutations appear to be predominant mechanisms for senescence induction in hepatocytes $^{136,137}$ although telomere damage is closely associated with oxidative stress. ${ }^{61}$

The hepatocyte's role in the metabolism of endo and xenobiotics (including toxins such as alcohol) results in a constant wave of insults that may compromise their homeostatic balance toward apoptosis, regeneration, or senescence. However, given the complexity and variety of conditions that affect the hepatocytes, the mechanisms that lead to the establishment of primary senescence in this cell type need further clarification.

\section{Other Liver Populations and Cellular Senescence}

The role of the hepatic stellate cells (HSCs) in liver disease is intimately related to fibrogenesis, as activated HSCs secrete an excess of ECM components such as collagens and MMP that alter the architecture of the liver and compromise the function of its cells. HSC senescence reduces ECM deposition and increases the level of ECM-degrading enzymes to limit and reverse fibrogenesis. ${ }^{19}$ Conversely, a deficient senescent response results in exacerbated fibrosis as HSCs continue to proliferate and deposit ECM. ${ }^{19}$

Multiple inductors of senescence have been described in activated HSCs including an increased sensitivity to DNA damage in comparison to quiescent HSCs. ${ }^{176}$ For example, upregulation of IL22 promotes HSC senescence and inhibits the expression of $\alpha$ SMA. ${ }^{177}$ Indeed, mice overexpressing IL22 have reduced levels of fibrosis. ${ }^{177}$

Accumulation of matricellular protein $\mathrm{CCN} 1$ in hepatocytes of human cirrhotic livers induces senescence in HSCs and portal fibroblasts through ROS accumulation and an excessive production of integrin $\alpha 6 \beta 1{ }^{20}$ In fact, HSC senescence was required for CCN1 to reverse hepatic fibrosis, and although $\mathrm{CCN} 1$ is not essential for liver function or its development, CCN1 deletion in hepatocytes results in exacerbated fibrosis concomitant with a deficient senescent response. ${ }^{20}$ IGF1 is also able to induce HSC senescence and limit fibrosis in a p53-dependent manner. ${ }^{178}$ Indeed, treatment with recombinant IGF1 limits fibrosis by promoting HSCs' senescence via PPAR $/$ p53 activation. ${ }^{179}$ Further mechanisms of senescence activation in HSCs involve substance-P (SP)/NK-1R axis. ${ }^{180}$ Consistent with other studies linking HSC senescence and fibrosis, mice treated with an NK-1R inhibitor display enhanced HSCs' senescence and a reduction in fibrogenesis. ${ }^{180}$

In contrast, Yoshimoto et al reported the opposite effects with deoxycholic acid (DCA), which caused DNA damage in HSC and was shown to provoke a SASP phenotype, promoting fibrosis. ${ }^{181}$ Without resolution, chronic exposure to HSCSASP promotes fibrosis and may leave patients with NASH susceptible to HCC development. In addition, HSCs appear to have longer telomeres in comparison with hepatocytes in chronic liver disease, ${ }^{133,146}$ potentially indicating that HSCs are less prone to establish a telomere-dependent senescent response, although the biological implications of this finding require further clarification.

To summarize, multiple studies appear to indicate that senescence in HSCs is a beneficial mechanism to avoid excessive fibrosis, although more details are required to fully understand the mechanisms that lead to this phenotype and how to manipulate them to alleviate this burden.

Other liver populations are susceptible to the implementation of cellular senescence, with variable results. 
Senescence in lymphocytes has been described in chronic viral hepatitis (CD4,$+{ }^{182} \mathrm{CD} 3+,{ }^{149,183,184}$ and CD8 $+{ }^{185} \mathrm{~T}$ cells), cirrhosis, ${ }^{136}$ and liver transplant recipients. ${ }^{186}$ This phenotype has been associated with increased fibrogenesis, immune exhaustion, and viral persistence. ${ }^{183}$

NK cell receptor (NKG2D) has also been identified as a crucial factor for the regulation of immune surveillance and protection against liver fibrosis by recognizing MICA and ULBP2 in senescent-activated HSCs. ${ }^{187}$

Liver-resident macrophages also participate in the senescent phenotype during paracetamol overdose by spreading senescence to bystander cells via the TGF $\beta 1$ ligand. ${ }^{132}$ Senescent HSCs also release factors such as IFN-c and IL6 that induce an M1 shift in liver-resident macrophages, promoting immune surveillance. ${ }^{188}$ Furthermore, given the association of autophagy and senescence ${ }^{189}$ and the recent description of "macroph-aging" in old mice, where senescence spreads to immune cells aggravating the pathology, ${ }^{30}$ we predict that the number of studies relating macrophages and senescence will increase in the coming years.

Finally, aged liver sinusoidal endothelial cells (LSECs) express high levels of p16, ${ }^{190}$ IL1, and IL6, ${ }^{191}$ concomitant to microcirculatory dysfunction and pseudocapillarization. ${ }^{191}$ LSECs isolated from $\mathrm{p} 19^{\mathrm{ARF}}-\mid-$ mice are able to escape senescence in vitro without evidencing signs of tumorigenesis $^{192}$ and elimination of p16+ LSECs disrupts the blood-tissue barriers inducing perivascular fibrosis associated with health deterioration, ${ }^{190}$ evidencing the importance of senescence in the maintenance of homeostasis in this cell type.

\section{Cellular Senescence and Liver Carcinogenesis}

Senescence has long been considered an antitumoral mechanism. ${ }^{13}$ In the liver, examples include the establishment of senescence in premalignant hepatocytes to limit cancer development, ${ }^{92}$ SASP-dependent recruitment of immune cells to remove senescent hepatocytes and prevent malignant transformation, ${ }^{93,193}$ and induction of senescence by means of ROC1 ablation to suppress further growth of malignant hepatocytes. ${ }^{194}$ Moreover, a defective senescent response is associated with the onset and progression of several liver tumors. ${ }^{93,195}$

However, it is now clear that senescence may also trigger liver carcinogenesis. Senescence has been associated with the pathophysiology of cholangiocarcinoma by promoting tumor development. ${ }^{196}$ Furthermore, it has also been associated with hepatocellular carcinoma (HCC) development, ${ }^{39}$ where a "senescence-bypass" (product of senescence's effectors inactivation) leads to DNA damage and chromosomal instability that characterize the progression toward malignancy. ${ }^{197}$ Other mechanisms of HCC development include enterohepatic circulation of DCA (a secondary bile acid produced by gut bacteria). This metabolite promotes a SASP phenotype in HSC, facilitating the development of HCC. ${ }^{181}$

Although these results demonstrate the importance of senescence in liver carcinogenesis, more studies are required to understand and manipulate senescence to prevent and/or treat liver cancer.

\section{Cellular Senescence and Mechanisms of Liver Regeneration}

The liver is an organ with exceptional regenerative properties. During homeostasis, turnover of hepatocytes is modest with $<0.5 \%$ proliferating at any given time. ${ }^{198}$ However, the liver is capable of completely restoring its mass from the remaining tissue after $75 \%$ resection, showing a remarkable ability to enter the cell cycle to restore liver mass. ${ }^{199}$

Hepatocyte death followed by the activation of proliferative and inflammatory pathways is traditionally viewed as the main regenerative mechanism in the liver. ${ }^{199}$ Liver regeneration is a complex process that can dramatically differ depending on the type of injury, but commonly involves a multicellular response, restoration of the innateimmunity landscape, and revascularization of damaged areas. Within this complex process, senescence appears to play an important role in the mechanisms that determine successful or failed regeneration.

Incidence of liver disease (as well as poorer outcomes) increases with age while the regenerative capacity of the organ decreases. ${ }^{127}$ Accumulation of senescent hepatocytes with age decreases their regenerative rate ${ }^{129,200}$ and, as a consequence, complete restoration of liver mass after partial hepatectomy $(\mathrm{PH})$ is delayed. ${ }^{201-203}$

In PH (a well-established model of liver regeneration) there is a careful coordination between cell proliferation and cell death that defines the compensatory growth of the organ. ${ }^{199}$ In this setting, several studies have identified senescent markers p21 and p27 in hepatocytes, ${ }^{204-206}$ with p21 reaching maximum levels in a p53-independent fashion at 48 hours after peak DNA synthesis. ${ }^{200,205}$ The hepatocytes of p21-deficient mice progress faster into the DNA synthesis phase, while p21 overexpression impairs hepatocyte proliferation after $\mathrm{PH}^{205,207}$ Furthermore, secondary hepatocyte senescence (in a model in which primary senescence is induced in cholangiocytes) failed to regenerate after 48 hours of $\mathrm{PH}$, suggesting that senescence controls an effective liver mass recovery. ${ }^{103}$

In fact, hepatocytes in adult mouse livers subjected to $\mathrm{PH}$ presented high levels of p21 expression and SASP factors but lacked other senescent markers such as p16 or SABGal. ${ }^{200}$ Although p21 alone may not represent a standard senescent phenotype, genetic deletion of p21 partially rescued liver regeneration. Furthermore, treatment with the senolytic drug ABT737 decreased p21 and SASP expression while improving liver regeneration, highlighting its potential for regenerative-based treatments. ${ }^{200}$

Overall, these results suggest that senescence is a protective mechanism at 48 hours after PH (when the rate of DNA damage peaks alongside the increase in DNA synthesis). However, if the balance between proliferation and senescence in the remaining hepatocytes tilts toward senescence, the regenerative ability of the liver will be compromised, although senotherapeutics showed promising results as potential enhancers of regeneration. ${ }^{200}$ 
Senescence might also be a control mechanism to prevent excessive growth beyond the point of repair, where the liver function is already restored. Similar mechanisms of developmental senescence have been described to pattern embryo structures, again in a p21-dependent and p53-independent manner. ${ }^{27,28}$

The SASP might be partially responsible for this response, as it has been shown to induce cellular plasticity, ${ }^{18}$ activate stem cells, ${ }^{18}$ and provide signals critical for cellular reprograming. ${ }^{17}$ A murine model of hepatocyte senescence subjected to further dietary damage shows a strong activation of biliary epithelial cells (BECs) with bipotential capacity to become cholangiocytes or hepatocytes and restore liver mass and function. ${ }^{208,209}$ This suggests that in a situation where senescence in the hepatic parenchyma renders this population unable to proliferate and repair the injury, the liver still retains alternative regenerative pathways based on stem cell-related mechanisms to prevent further damage, regenerate the damaged areas, and restore liver function. Further studies will define in the future if the SASP of these senescent hepatocytes includes factors that facilitate this regenerative response (-Fig. 2).

\section{Targeting Cellular Senescence: the Future of Therapeutics in Liver Disease?}

Cellular senescence is a complex phenotype and its consequences for liver homeostasis, disease, and regeneration are still under study. In the liver, senescence is a highly antagonistic pleiotropic response, dependent on a spatial/temporal context. As a protective element, short-term senescence is associated with antitumoral, hepatoprotective, antifibrotic, and proregenerative mechanisms. ${ }^{11,15}$ However, it has also been linked to impaired regeneration, carcinogenesis, and progression of inflammation. 7,11,15,31

Cellular senescence underlies most types of chronic liver disease, where the persistence of inflammation and the alteration of the fine balance between regeneration and destruction might lead to the implementation of senescence. However, murine models have shown that senescence per se is able to recapitulate the onset key events of several liver conditions, suggesting a causative role for this phenomenon. ${ }^{103}$

Either as a triggering factor or a consequence of the pathology, senescence has proven to be a relevant factor in liver disease. As so, several groups propose to use senescence markers to help establish diagnosis and severity of chronic conditions (such as p21 in CR, ${ }^{95}$ chitotriosidase in $\mathrm{HCV},{ }^{149}$ or SMP30 in NAFLD ${ }^{166}$ ). However, the necessity of finding several factors and lack of superficial noninvasive markers complicate the use of senescence as a diagnostic tool.

Studies looking at the effects of preventing, reducing, or inducing senescence in the context of liver disease are currently under way. For example, manipulation of host senescence could block hepatitis virus infection, ${ }^{142}$ while inhibiting immune senescence could prevent the spread of hepatitis viruses. ${ }^{149}$ Induction of senescence in HSCs could reduce fibrosis, ${ }^{19}$ while blocking hepatocellular senescence might be advantageous to reverse cirrhosis ${ }^{133,138}$ and treat NAFLD. ${ }^{137}$ Blocking of SASP factors could prevent the detri- mental effects of cholangiocyte senescence in $\mathrm{PBC}^{103}$ and promote liver regeneration in the setting of acute liver damage. ${ }^{132}$ Furthermore, controlling senescence-related pathways, such as autophagy or apoptosis, might be another strategy to manipulate this phenotype therapeutically. ${ }^{46}$

In line with these findings, several groups have reported the use of novel agents able to induce senescence (curcumin, ${ }^{179}$ tetramethylpyrazine, ${ }^{210}$ retinoic acid, ${ }^{211}$ or dihydroartemisinin ${ }^{212}$ in HSCs) or eliminate senescent cells by means of senolytics (such as A- $1331852,{ }^{106}$ dasatinib + quercetin $^{82}$ ) to restrain the damage and induce liver regeneration. Selective elimination of senescent cells may be key to the success of senolytics as demonstrated recently in a mouse model of HCC in which therapy-induced senescent cancer cells were specifically targeted with the MTOR inhibitor AZD8055, and the survival time was almost doubled. ${ }^{213}$

Partial blockage of SASP factors has also proven to be a useful strategy to manipulate senescence effects. ${ }^{103,132}$ Other strategies aimed at modulating senescence in other tissues might be useful for treating liver conditions, such as metformin administration, ${ }^{214}$ caloric restriction, ${ }^{215}$ or use of nanocarriers. ${ }^{216}$

Modulation of senescence by means of senolytics, senomorphics, or SASP-blocking agents could also help us to manipulate the intrinsic regenerative abilities of the liver. By doing so we might be able to promote an endogenous BECdependent reparative response and improve the engraftment and proliferation of transplanted cells used in cell therapy. ${ }^{208}$

The aging population, combined with the increasing incidence of liver disease, has sparked a new wave of interest in senescence related to hepatology. Because of the inherent complexities of the senescence process, it will be crucial to understand the mechanisms and consequences of senescence in liver disease to develop effective senescence-targeted therapies.

Moreover, study of emerging fields such as epigenetics ${ }^{217,218}$ that could influence the senescence response in the liver in association with other pathologies (such as obesity ${ }^{219}$ ), "macroph-aging" and its implications for immune surveillance ${ }^{30,220}$ and its associated "inflammaging"221,222 (characterized by the upregulation of the inflammatory response that occurs with advancing age), will immensely contribute to the understanding of liver disease and regeneration.

\section{Main Concepts and Learning Points}

- Cellular senescence plays a relevant role in the occurrence and development of liver disease.

- We provide a comprehensive list of senescence markers and related mechanisms in liver homeostasis and disease.

- We discuss the implications of cellular senescence for liver regeneration.

- Manipulation of cellular senescence as a potential therapeutic intervention.

\section{Funding}

This study was supported by Research Councils UK and Medical Research Council (MR/P016839/1, UKRMP, and MR/R015635/1). 


\section{Conflict of Interest}

The authors declare they have no conflict of interest.

\section{References}

1 Kirkwood TB. Where will it all end? Lancet 2001;357(9256):576

2 Source: Office for National Statistics, UK. Accessed February 11, 2020 at: https://www.ons.gov.uk/peoplepopulationandcommunity/ birthsdeathsandmarriages/lifeexpectancies/articles/howhaslifeexpectancychangedovertime/2015-09-09

3 Kirkwood TB, Austad SN. Why do we age? Nature 2000;408 (6809):233-238

4 Carrel A. On the permanent life of tissue outside of the organism. J Exp Med 1912;15(05):516-528

5 Friedman DM. The Immortalists: Charles Lindbergh, Dr Alexis Carrel, and Their Daring Quest to Live Forever. 2nd ed. New York, NY: Harper Collins; 2008:12

6 Shay JW, Wright WE. Hayflick, his limit, and cellular ageing. Nat Rev Mol Cell Biol 2000;1(01):72-76

7 Campisi J. Replicative senescence: an old lives' tale? Cell 1996;84 (04):497-500

8 Hayflick L, Moorhead PS. The serial cultivation of human diploid cell strains. Exp Cell Res 1961;25:585-621

9 Forbes SJ, Newsome PN. Liver regeneration - mechanisms and models to clinical application. Nat Rev Gastroenterol Hepatol 2016;13(08):473-485

10 Childs BG, Baker DJ, Kirkland JL, Campisi J, van Deursen JM. Senescence and apoptosis: dueling or complementary cell fates? EMBO Rep 2014;15(11):1139-1153

11 Gorgoulis V, Adams PD, Alimonti A, et al. Cellular senescence: defining a path forward. Cell 2019;179(04):813-827

12 Wang Y, Xu Q, Sack L, Kang C, Elledge SJ. A gain-of-function senescence bypass screen identifies the homeobox transcription factor DLX2 as a regulator of ATM-p53 signaling. Genes Dev 2016;30(03):293-306

13 Lee S, Schmitt CA. The dynamic nature of senescence in cancer. Nat Cell Biol 2019;21(01):94-101

14 Hanahan D, Weinberg RA. Hallmarks of cancer: the next generation. Cell 2011;144(05):646-674

15 Muñoz-Espín D, Serrano M. Cellular senescence: from physiology to pathology. Nat Rev Mol Cell Biol 2014;15(07):482-496

16 Demaria M, Ohtani N, Youssef SA, et al. An essential role for senescent cells in optimal wound healing through secretion of PDGF-AA. Dev Cell 2014;31(06):722-733

17 Mosteiro L, Pantoja C, Alcazar N, et al. Tissue damage and senescence provide critical signals for cellular reprogramming in vivo. Science 2016;354(6315):1020-1030

18 Ritschka B, Storer M, Mas A, et al. The senescence-associated secretory phenotype induces cellular plasticity and tissue regeneration. Genes Dev 2017;31(02):172-183

19 Krizhanovsky V, Yon M, Dickins RA, et al. Senescence of activated stellate cells limits liver fibrosis. Cell 2008;134(04):657-667

$20 \mathrm{Kim} \mathrm{KH}$, Chen CC, Monzon RI, Lau LF. Matricellular protein CCN1 promotes regression of liver fibrosis through induction of cellular senescence in hepatic myofibroblasts. Mol Cell Biol 2013;33 (10):2078-2090

21 Wolstein JM, Lee DH, Michaud J, Buot V, Stefanchik B, Plotkin MD. INK4a knockout mice exhibit increased fibrosis under normal conditions and in response to unilateral ureteral obstruction. Am J Physiol Renal Physiol 2010;299(06):F1486-F1495

22 Zhu F, Li Y, Zhang J, et al. Senescent cardiac fibroblast is critical for cardiac fibrosis after myocardial infarction. PLoS One 2013;8 (09):e74535

23 Jun JI, Lau LF. Cellular senescence controls fibrosis in wound healing. Aging (Albany NY) 2010;2(09):627-631

24 Besancenot R, Chaligné R, Tonetti $C$, et al. A senescence-like cellcycle arrest occurs during megakaryocytic maturation: implica- tions for physiological and pathological megakaryocytic proliferation. PLoS Biol 2010;8(09):e1000476

25 Rajagopalan S, Long EO. Cellular senescence induced by CD158d reprograms natural killer cells to promote vascular remodeling. Proc Natl Acad Sci U S A 2012;109(50):20596-20601

26 Chuprin A, Gal H, Biron-Shental T, et al. Cell fusion induced by ERVWE1 or measles virus causes cellular senescence. Genes Dev 2013;27(21):2356-2366

27 Muñoz-Espín D, Cañamero M, Maraver A, et al. Programmed cell senescence during mammalian embryonic development. Cell 2013;155(05):1104-1118

28 Storer M, Mas A, Robert-Moreno A, et al. Senescence is a developmental mechanism that contributes to embryonic growth and patterning. Cell 2013;155(05):1119-1130

29 Franceschi C, Campisi J. Chronic inflammation (inflammaging) and its potential contribution to age-associated diseases. J Gerontol A Biol Sci Med Sci 2014;69(Suppl 1):S4-S9

30 Hall BM, Balan V, Gleiberman AS, et al. Aging of mice is associated with p16(Ink4a)- and $\beta$-galactosidase-positive macrophage accumulation that can be induced in young mice by senescent cells. Aging (Albany NY) 2016;8(07):1294-1315

31 Coppé JP, Desprez PY, Krtolica A, Campisi J. The senescenceassociated secretory phenotype: the dark side of tumor suppression. Annu Rev Pathol 2010;5(01):99-118

32 Childs BG, Baker DJ, Wijshake T, Conover CA, Campisi J, van Deursen JM. Senescent intimal foam cells are deleterious at all stages of atherosclerosis. Science 2016;354(6311):472-477

33 Thompson PJ, Shah A, Ntranos V, Van Gool F, Atkinson M, Bhushan A. Targeted elimination of senescent beta cells prevents type 1 diabetes. Cell Metab 2019;29(05):1045.e10-1060.e10

34 Jeon OH, Kim C, Laberge RM, et al. Local clearance of senescent cells attenuates the development of post-traumatic osteoarthritis and creates a pro-regenerative environment. Nat Med 2017; 23(06):775-781

35 Palmer AK, Xu M, Zhu Y, et al. Targeting senescent cells alleviates obesity-induced metabolic dysfunction. Aging Cell 2019;18(03): e12950

36 Bussian TJ, Aziz A, Meyer CF, Swenson BL, van Deursen JM, Baker DJ. Clearance of senescent glial cells prevents tau-dependent pathology and cognitive decline. Nature 2018;562(7728): 578-582

37 López-Otín C, Blasco MA, Partridge L, Serrano M, Kroemer G. The hallmarks of aging. Cell 2013;153(06):1194-1217

38 Dimri GP, Lee X, Basile G, et al. A biomarker that identifies senescent human cells in culture and in aging skin in vivo. Proc Natl Acad Sci U S A 1995;92(20):9363-9367

39 Paradis V, Youssef N, Dargère D, et al. Replicative senescence in normal liver, chronic hepatitis $\mathrm{C}$, and hepatocellular carcinomas. Hum Pathol 2001;32(03):327-332

40 Melk A, Schmidt BM, Braun H, et al. Effects of donor age and cell senescence on kidney allograft survival. Am J Transplant 2009;9 (01):114-123

41 Erusalimsky JD, Kurz DJ. Cellular senescence in vivo: its relevance in ageing and cardiovascular disease. Exp Gerontol 2005;40(89):634-642

42 Jeyapalan JC, Ferreira M, Sedivy JM, Herbig U. Accumulation of senescent cells in mitotic tissue of aging primates. Mech Ageing Dev 2007;128(01):36-44

43 Rodier F, Campisi J. Four faces of cellular senescence. J Cell Biol 2011;192(04):547-556

44 Beauséjour CM, Krtolica A, Galimi F, et al. Reversal of human cellular senescence: roles of the p53 and p16 pathways. EMBO J 2003;22(16):4212-4222

45 Sharpless NE, Sherr CJ. Forging a signature of in vivo senescence. Nat Rev Cancer 2015;15(07):397-408

46 Yosef R, Pilpel N, Tokarsky-Amiel R, et al. Directed elimination of senescent cells by inhibition of BCL-W and BCL-XL. Nat Commun 2016;7:11190 
47 d'Adda di Fagagna F, Reaper PM, Clay-Farrace L, et al. A DNA damage checkpoint response in telomere-initiated senescence. Nature 2003;426(6963):194-198

48 d'Adda di Fagagna F. Living on a break: cellular senescence as a DNA-damage response. Nat Rev Cancer 2008;8(07):512-522

49 Rodier F, Coppé JP, Patil CK, et al. Persistent DNA damage signalling triggers senescence-associated inflammatory cytokine secretion. Nat Cell Biol 2009;11(08):973-979

50 Ivanov A, Pawlikowski J, Manoharan I, et al. Lysosome-mediated processing of chromatin in senescence. J Cell Biol 2013;202(01): 129-143

$51 \mathrm{Li} \mathrm{T}$, Chen ZJ. The cGAS-cGAMP-STING pathway connects DNA damage to inflammation, senescence, and cancer. J Exp Med 2018;215(05):1287-1299

52 Narita M, Nũnez S, Heard E, et al. Rb-mediated heterochromatin formation and silencing of E2F target genes during cellular senescence. Cell 2003;113(06):703-716

53 Di Micco R, Sulli G, Dobreva M, et al. Interplay between oncogene-induced DNA damage response and heterochromatin in senescence and cancer. Nat Cell Biol 2011;13(03):292-302

54 Aird KM, Zhang R. Detection of senescence-associated heterochromatin foci (SAHF). Methods Mol Biol 2013;965:185-196

55 Swanson EC, Manning B, Zhang H, Lawrence JB. Higher-order unfolding of satellite heterochromatin is a consistent and early event in cell senescence. J Cell Biol 2013;203(06):929-942

56 Kuilman T, Michaloglou C, Mooi WJ, Peeper DS. The essence of senescence. Genes Dev 2010;24(22):2463-2479

57 Dou Z, Ghosh K, Vizioli MG, et al. Cytoplasmic chromatin triggers inflammation in senescence and cancer. Nature 2017;550 (7676):402-406

58 Podrimaj-Bytyqi A, Borovečki A, Selimi Q Manxhuka-Kerliu S, Gashi G, Elezaj IR. The frequencies of micronuclei, nucleoplasmic bridges and nuclear buds as biomarkers of genomic instability in patients with urothelial cell carcinoma. Sci Rep 2018;8(01):17873

59 Shimi T, Butin-Israeli V, Adam SA, et al. The role of nuclear lamin B1 in cell proliferation and senescence. Genes Dev 2011;25(24): 2579-2593

60 Freund A, Laberge RM, Demaria M, Campisi J. Lamin B1 loss is a senescence-associated biomarker. Mol Biol Cell 2012;23(11): 2066-2075

61 Shay JW, Wright WE. Telomeres and telomerase: three decades of progress. Nat Rev Genet 2019;20(05):299-309

62 Victorelli S, Passos JF. Telomeres and Cell senescence - size matters not. EBioMedicine 2017;21:14-20

63 Muñoz-Lorente MA, Cano-Martin AC, Blasco MA. Mice with hyper-long telomeres show less metabolic aging and longer lifespans. Nat Commun 2019;10(01):4723

64 Passos JF, Nelson G, Wang C, et al. Feedback between p21 and reactive oxygen production is necessary for cell senescence. Mol Syst Biol 2010;6:347

65 Correia-Melo C, Marques FDM, Anderson R, et al. Mitochondria are required for pro-ageing features of the senescent phenotype. EMBO J 2016;35(07):724-742

66 Birch J, Victorelli S, Rahmatika D, et al. Telomere dysfunction and senescence-associated pathways in bronchiectasis. Am J Respir Crit Care Med 2016;193(08):929-932

67 Jung T, Bader N, Grune T. Lipofuscin: formation, distribution, and metabolic consequences. Ann N Y Acad Sci 2007;1119:97-111

68 Nardella C, Clohessy JG, Alimonti A, Pandolfi PP. Pro-senescence therapy for cancer treatment. Nat Rev Cancer 2011;11(07): 503-511

69 Debacq-Chainiaux F, Erusalimsky JD, Campisi J, Toussaint O. Protocols to detect senescence-associated beta-galactosidase (SA-betagal) activity, a biomarker of senescent cells in culture and in vivo. Nat Protoc 2009;4(12):1798-1806

70 Georgakopoulou EA, Tsimaratou K, Evangelou K, et al. Specific lipofuscin staining as a novel biomarker to detect replicative and stress-induced senescence. A method applicable in cryo-preserved and archival tissues. Aging (Albany NY) 2013;5(01):37-50

71 Evangelou K, Lougiakis N, Rizou SV, et al. Robust, universal biomarker assay to detect senescent cells in biological specimens. Aging Cell 2017;16(01):192-197

72 Haugstetter AM, Loddenkemper C, Lenze D, et al. Cellular senescence predicts treatment outcome in metastasised colorectal cancer. Br J Cancer 2010;103(04):505-509

73 Deschênes-Simard X, Gaumont-Leclerc MF, Bourdeau V, et al. Tumor suppressor activity of the ERK/MAPK pathway by promoting selective protein degradation. Genes Dev 2013;27(08): 900-915

74 Karisch R, Fernandez M, Taylor P, et al. Global proteomic assessment of the classical protein-tyrosine phosphatome and "Redoxome". Cell 2011;146(05):826-840

75 Nyström T. Role of oxidative carbonylation in protein quality control and senescence. EMBO J 2005;24(07):1311-1317

76 Ogrodnik M, Salmonowicz H, Gladyshev VN. Integrating cellular senescence with the concept of damage accumulation in aging: Relevance for clearance of senescent cells. Aging Cell 2019;18 (01):e12841

77 Vernier M, Bourdeau V, Gaumont-Leclerc MF, et al. Regulation of E2Fs and senescence by PML nuclear bodies. Genes Dev 2011;25 (01):41-50

78 Hernandez-Segura A, Nehme J, Demaria M. Hallmarks of cellular senescence. Trends Cell Biol 2018;28(06):436-453

79 Campisi J, d'Adda di Fagagna F. Cellular senescence: when bad things happen to good cells. Nat Rev Mol Cell Biol 2007;8(09): 729-740

80 Aravinthan A, Verma S, Coleman N, Davies S, Allison M, Alexander G. Vacuolation in hepatocyte nuclei is a marker of senescence. J Clin Pathol 2012;65(06):557-560

81 Ademowo OS, Dias HKI, Burton DGA, Griffiths HR. Lipid (per) oxidation in mitochondria: an emerging target in the ageing process? Biogerontology 2017;18(06):859-879

82 Ogrodnik M, Miwa S, Tchkonia T, et al. Cellular senescence drives age-dependent hepatic steatosis. Nat Commun 2017;8:15691

83 Kaplon J, Zheng L, Meissl K, et al. A key role for mitochondrial gatekeeper pyruvate dehydrogenase in oncogene-induced senescence. Nature 2013;498(7452):109-112

84 Korolchuk VI, Miwa S, Carroll B, von Zglinicki T. Mitochondria in cell senescence: is mitophagy the weakest link? EBioMedicine 2017;21:7-13

85 Passos JF, Saretzki G, Ahmed S, et al. Mitochondrial dysfunction accounts for the stochastic heterogeneity in telomere-dependent senescence. PLoS Biol 2007;5(05):e110

86 Acosta JC, O'Loghlen A, Banito A, et al. Chemokine signaling via the CXCR2 receptor reinforces senescence. Cell 2008;133(06): 1006-1018

87 Kuilman T, Peeper DS. Senescence-messaging secretome: SMSing cellular stress. Nat Rev Cancer 2009;9(02):81-94

88 Hoare M, Ito Y, Kang TW, et al. NOTCH1 mediates a switch between two distinct secretomes during senescence. Nat Cell Biol 2016;18(09):979-992

89 Basisty N, Kale A, Jeon OH, et al. A proteomic atlas of senescenceassociated secretomes for aging biomarker development. PLoS Biol 2020;18(01):e3000599

90 Biran A, Perelmutter M, Gal H, et al. Senescent cells communicate via intercellular protein transfer. Genes Dev 2015;29(08): 791-802

91 Borghesan M, Fafián-Labora J, Eleftheriadou O, et al. Small extracellular vesicles are key regulators of non-cell autonomous intercellular communication in senescence via the interferon protein IFITM3. Cell Rep 2019;27(13):3956.e6-3971.e6

92 Kang TW, Yevsa T, Woller N, et al. Senescence surveillance of premalignant hepatocytes limits liver cancer development. Nature 2011;479(7374):547-551 
93 Xue W, Zender L, Miething C, et al. Senescence and tumour clearance is triggered by p53 restoration in murine liver carcinomas. Nature 2007;445(7128):656-660

94 Rakhra K, Bachireddy P, Zabuawala T, et al. CD4(+) T cells contribute to the remodeling of the microenvironment required for sustained tumor regression upon oncogene inactivation. Cancer Cell 2010;18(05):485-498

95 Lunz JG III, Contrucci S, Ruppert K, et al. Replicative senescence of biliary epithelial cells precedes bile duct loss in chronic liver allograft rejection: increased expression of p21(WAF1/Cip1) as a disease marker and the influence of immunosuppressive drugs. Am J Pathol 2001;158(04):1379-1390

96 Sasaki M, Ikeda H, Haga H, Manabe T, Nakanuma Y. Frequent cellular senescence in small bile ducts in primary biliary cirrhosis: a possible role in bile duct loss. J Pathol 2005;205(04): 451-459

97 Brain JG, Robertson H, Thompson E, et al. Biliary epithelial senescence and plasticity in acute cellular rejection. Am J Transplant 2013;13(07):1688-1702

98 Demirci G, Nashan B, Pichlmayr R. Fibrosis in chronic rejection of human liver allografts: expression patterns of transforming growth factor-TGFbeta1 and TGF-beta3. Transplantation 1996; 62(12):1776-1783

99 Gutierrez-Reyes G, del Carmen Garcia de Leon M, Varela-Fascinetto G, et al. Cellular senescence in livers from children with end stage liver disease. PLoS One 2010;5(04):e10231

100 Sanada Y, Kawano Y, Miki A, et al. Maternal grafts protect daughter recipients from acute cellular rejection after pediatric living donor liver transplantation for biliary atresia. Transpl Int 2014;27(04):383-390

101 Dyson JK, Beuers U, Jones DEJ, Lohse AW, Hudson M. Primary sclerosing cholangitis. Lancet 2018;391(10139):2547-2559

102 Tabibian JH, O'Hara SP, Splinter PL, Trussoni CE, LaRusso NF. Cholangiocyte senescence by way of $\mathrm{N}$-ras activation is a characteristic of primary sclerosing cholangitis. Hepatology 2014;59 (06):2263-2275

103 Ferreira-Gonzalez S, Lu WY, Raven A, et al. Paracrine cellular senescence exacerbates biliary injury and impairs regeneration. Nat Commun 2018;9(01):1020

104 Sasaki M, Ikeda H, Sato Y, Nakanuma Y. Decreased expression of Bmi1 is closely associated with cellular senescence in small bile ducts in primary biliary cirrhosis. Am J Pathol 2006;169(03): 831-845

105 Loarca L, De Assuncao TM, Jalan-Sakrikar N, et al. Development and characterization of cholangioids from normal and diseased human cholangiocytes as an in vitro model to study primary sclerosing cholangitis. Lab Invest 2017;97(11):1385-1396

106 Moncsek A, Al-Suraih MS, Trussoni CE, et al. Targeting senescent cholangiocytes and activated fibroblasts with B-cell lymphomaextra large inhibitors ameliorates fibrosis in multidrug resistance 2 gene knockout (Mdr2 ${ }^{-/-}$) mice. Hepatology 2018;67(01):247-259

107 O'Hara SP, Splinter PL, Trussoni CE, et al. The transcription factor ETS1 promotes apoptosis resistance of senescent cholangiocytes by epigenetically up-regulating the apoptosis suppressor BCL2L1. J Biol Chem 2019;294(49):18698-18713

108 Popov Y, Patsenker E, Fickert P, Trauner M, Schuppan D. Mdr2 (Abcb4)-/- mice spontaneously develop severe biliary fibrosis via massive dysregulation of pro- and antifibrogenic genes. J Hepatol 2005;43(06):1045-1054

109 Lukivskaya O, Zavodnik L, Knas M, Buko V. Antioxidant mechanism of hepatoprotection by ursodeoxycholic acid in experimental alcoholic steatohepatitis. Adv Med Sci 2006;51:54-59

110 Tabibian JH, O'Hara SP, Trussoni CE, et al. Absence of the intestinal microbiota exacerbates hepatobiliary disease in a murine model of primary sclerosing cholangitis. Hepatology 2016;63 (01):185-196

111 Zhou T, Wu N, Meng F, et al. Knockout of secretin receptor reduces biliary damage and liver fibrosis in $\mathrm{Mdr}^{-1-}$ mice by diminishing senescence of cholangiocytes. Lab Invest 2018;98 (11):1449-1464

112 Carey EJ, Ali AH, Lindor KD. Primary biliary cirrhosis. Lancet 2015;386(10003):1565-1575

113 Harada K, Furubo S, Ozaki S, Hiramatsu K, Sudo Y, Nakanuma Y. Increased expression of WAF1 in intrahepatic bile ducts in primary biliary cirrhosis relates to apoptosis. J Hepatol 2001; 34(04):500-506

114 Sasaki M, Ikeda H, Yamaguchi J, Nakada S, Nakanuma Y. Telomere shortening in the damaged small bile ducts in primary biliary cirrhosis reflects ongoing cellular senescence. Hepatology 2008; 48(01):186-195

115 Sasaki M, Miyakoshi M, Sato Y, Nakanuma Y. Modulation of the microenvironment by senescent biliary epithelial cells may be involved in the pathogenesis of primary biliary cirrhosis. J Hepatol 2010;53(02):318-325

116 Sasaki M, Ikeda H, Yamaguchi J, Miyakoshi M, Sato Y, Nakanuma Y. Bile ductular cells undergoing cellular senescence increase in chronic liver diseases along with fibrous progression. Am J Clin Pathol 2010;133(02):212-223

117 Sasaki M, Miyakoshi M, Sato Y, Nakanuma Y. Chemokine-chemokine receptor CCL2-CCR2 and CX3CL1-CX3CR1 axis may play a role in the aggravated inflammation in primary biliary cirrhosis. Dig Dis Sci 2014;59(02):358-364

118 Sasaki M, Miyakoshi M, Sato Y, Nakanuma Y. Increased expression of mitochondrial proteins associated with autophagy in biliary epithelial lesions in primary biliary cirrhosis. Liver Int 2013;33(02):312-320

119 Sasaki M, Kakuda Y, Miyakoshi M, Sato Y, Nakanuma Y. Infiltration of inflammatory cells expressing mitochondrial proteins around bile ducts and in biliary epithelial layer may be involved in the pathogenesis in primary biliary cirrhosis. J Clin Pathol 2014;67(06):470-476

120 Young ARJ, Narita M, Ferreira M, et al. Autophagy mediates the mitotic senescence transition. Genes Dev 2009;23(07):798-803

121 Sasaki M, Miyakoshi M, Sato Y, Nakanuma Y. A possible involvement of p62/sequestosome-1 in the process of biliary epithelial autophagy and senescence in primary biliary cirrhosis. Liver Int 2012;32(03):487-499

122 Sasaki M, Miyakoshi M, Sato Y, Nakanuma Y. Autophagy mediates the process of cellular senescence characterizing bile duct damages in primary biliary cirrhosis. Lab Invest 2010;90(06): 835-843

123 Davalli P, Mitic T, Caporali A, Lauriola A, D'Arca D. ROS, cell senescence, and novel molecular mechanisms in aging and agerelated diseases. Oxid Med Cell Longev 2016;2016:3565127

124 Liguori I, Russo G, Curcio F, et al. Oxidative stress, aging, and diseases. Clin Interv Aging 2018;13:757-772

125 Strazzabosco M, Spirlí C, Okolicsanyi L. Pathophysiology of the intrahepatic biliary epithelium. J Gastroenterol Hepatol 2000;15 (03):244-253

126 Abe Y, Hines IN, Zibari G, et al. Mouse model of liver ischemia and reperfusion injury: method for studying reactive oxygen and nitrogen metabolites in vivo. Free Radic Biol Med 2009;46(01):1-7

127 Hoare M, Das T, Alexander G. Ageing, telomeres, senescence, and liver injury. J Hepatol 2010;53(05):950-961

128 Schmucker DL. Age-related changes in liver structure and function: Implications for disease? Exp Gerontol 2005;40(89):650-659

129 Wang MJ, Chen F, Li JX, et al. Reversal of hepatocyte senescence after continuous in vivo cell proliferation. Hepatology 2014;60 (01):349-361

130 Verma S, Tachtatzis P, Penrhyn-Lowe S, et al. Sustained telomere length in hepatocytes and cholangiocytes with increasing age in normal liver. Hepatology 2012;56(04):1510-1520

131 Wang C, Chen WJ, Wu YF, et al. The extent of liver injury determines hepatocyte fate toward senescence or cancer. Cell Death Dis 2018;9(05):575 
132 Bird TG, Müller M, Boulter L, et al. TGFß inhibition restores a regenerative response in acute liver injury by suppressing paracrine senescence. Sci Transl Med 2018;10(454):eaan1230

133 Wiemann SU, Satyanarayana A, Tsahuridu M, et al. Hepatocyte telomere shortening and senescence are general markers of human liver cirrhosis. FASEB J 2002;16(09):935-942

134 Ikeda H, Sasaki M, Sato Y, et al. Large cell change of hepatocytes in chronic viral hepatitis represents a senescent-related lesion. Hum Pathol 2009;40(12):1774-1782

135 Aravinthan A, Scarpini C, Tachtatzis P, et al. Hepatocyte senescence predicts progression in non-alcohol-related fatty liver disease. J Hepatol 2013;58(03):549-556

136 Calado RT, Brudno J, Mehta P, et al. Constitutional telomerase mutations are genetic risk factors for cirrhosis. Hepatology 2011; 53(05):1600-1607

137 Hartmann D, Srivastava U, Thaler M, et al. Telomerase gene mutations are associated with cirrhosis formation. Hepatology 2011;53(05):1608-1617

138 Rudolph KL, Chang S, Millard M, Schreiber-Agus N, DePinho RA. Inhibition of experimental liver cirrhosis in mice by telomerase gene delivery. Science 2000;287(5456):1253-1258

139 Wiemann SU, Satyanarayana A, Buer J, Kamino K, Manns MP, Rudolph KL. Contrasting effects of telomere shortening on organ homeostasis, tumor suppression, and survival during chronic liver damage. Oncogene 2005;24(09):1501-1509

140 Yosef R, Pilpel N, Papismadov N, et al. p21 maintains senescent cell viability under persistent DNA damage response by restraining JNK and caspase signaling. EMBO J 2017;36(15):2280-2295

141 Marshall A, Rushbrook S, Davies SE, et al. Relation between hepatocyte G1 arrest, impaired hepatic regeneration, and fibrosis in chronic hepatitis C virus infection. Gastroenterology 2005; 128(01):33-42

142 Sekoguchi S, Nakajima T, Moriguchi M, et al. Role of cell-cycle turnover and oxidative stress in telomere shortening and cellular senescence in patients with chronic hepatitis C. J Gastroenterol Hepatol 2007;22(02):182-190

143 Tachtatzis PM, Marshall A, Arvinthan A, et al. Chronic hepatitis B virus infection: the relation between hepatitis $B$ antigen expression, telomere length, senescence, inflammation and fibrosis. PLoS One 2015;10(05):e0127511

144 Wan Y, McDaniel K, Wu N, et al. Regulation of cellular senescence by miR-34a in alcoholic liver injury. Am J Pathol 2017;187(12): 2788-2798

145 Meng F, Ramos-Lorenzo S, Francis H, et al. Characterization of cellular senescence mechanisms in alcoholic liver injury. FASEB J 2017;31(Suppl 1):804.3

146 Aravinthan AD, Alexander GJM. Senescence in chronic liver disease: Is the future in aging? J Hepatol 2016;65(04):825-834

147 Papatheodoridi AM, Chrysavgis L, Koutsilieris M, Chatzigeorgiou A. The role of senescence in the development of nonalcoholic fatty liver disease and progression to nonalcoholic steatohepatitis. Hepatology 2020;71(01):363-374

148 Wood MJ, Gadd VL, Powell LW, Ramm GA, Clouston AD. Ductular reaction in hereditary hemochromatosis: the link between hepatocyte senescence and fibrosis progression. Hepatology 2014;59(03):848-857

149 Wandrer F, Han B, Liebig S, et al. Senescence mirrors the extent of liver fibrosis in chronic hepatitis $\mathrm{C}$ virus infection. Aliment Pharmacol Ther 2018;48(03):270-280

150 Aravinthan A, Pietrosi G, Hoare M, et al. Hepatocyte expression of the senescence marker p21 is linked to fibrosis and an adverse liver-related outcome in alcohol-related liver disease. PLoS One 2013;8(09):e72904

151 Tomita K, Teratani T, Suzuki T, et al. p53/p66Shc-mediated signaling contributes to the progression of non-alcoholic steatohepatitis in humans and mice. J Hepatol 2012;57(04):837-843

152 Zhang X, Zhou D, Strakovsky R, Zhang Y, Pan YX. Hepatic cellular senescence pathway genes are induced through histone mod- ifications in a diet-induced obese rat model. Am J Physiol Gastrointest Liver Physiol 2012;302(05):G558-G564

153 Richardson MM, Jonsson JR, Powell EE, et al. Progressive fibrosis in nonalcoholic steatohepatitis: association with altered regeneration and a ductular reaction. Gastroenterology 2007;133(01): 80-90

154 Laish I, Mannasse-Green B, Hadary R, et al. Telomere dysfunction in nonalcoholic fatty liver disease and cryptogenic cirrhosis. Cytogenet Genome Res 2016;150(02):93-99

155 Ping F, Li ZY, Lv K, et al. Deoxyribonucleic acid telomere length shortening can predict the incidence of non-alcoholic fatty liver disease in patients with type 2 diabetes mellitus. J Diabetes Investig 2017;8(02):174-180

156 Nguyen P, Valanejad L, Cast A, et al. Elimination of age-associated hepatic steatosis and correction of aging phenotype by inhibition of cdk4-C/EBP $\alpha-p 300$ axis. Cell Rep 2018;24(06): 1597-1609

157 Aravinthan A, Mells G, Allison M, et al. Gene polymorphisms of cellular senescence marker p21 and disease progression in nonalcohol-related fatty liver disease. Cell Cycle 2014;13(09):1489-1494

158 Karaman H, Karaman A, Donmez-Altuntas H, et al. Investigation of genome instability in patients with non-alcoholic steatohepatitis. World J Gastroenterol 2013;19(32):5295-5301

159 Nishida N, Yada N, Hagiwara S, Sakurai T, Kitano M, Kudo M. Unique features associated with hepatic oxidative DNA damage and DNA methylation in non-alcoholic fatty liver disease. J Gastroenterol Hepatol 2016;31(09):1646-1653

160 Hardy T, Zeybel M, Day CP, et al. Plasma DNA methylation: a potential biomarker for stratification of liver fibrosis in nonalcoholic fatty liver disease. Gut 2017;66(07):1321-1328

161 Hotta K, Kitamoto A, Kitamoto T, et al. Identification of differentially methylated region (DMR) networks associated with progression of nonalcoholic fatty liver disease. Sci Rep 2018;8(01): 13567

162 Nano J, Ghanbari M, Wang W, et al;BIOS consortium. Epigenomewide association study identifies methylation sites associated with liver enzymes and hepatic steatosis. Gastroenterology 2017;153(04):1096-1106.e2

163 Murphy SK, Yang H, Moylan CA, et al. Relationship between methylome and transcriptome in patients with nonalcoholic fatty liver disease. Gastroenterology 2013;145(05):1076-1087

164 Nakajima T, Nakashima T, Okada Y, et al. Nuclear size measurement is a simple method for the assessment of hepatocellular aging in non-alcoholic fatty liver disease: comparison with telomere-specific quantitative FISH and p21 immunohistochemistry. Pathol Int 2010;60(03):175-183

165 Arun P, Aleti V, Parikh K, Manne V, Chilukuri N. Senescence marker protein 30 (SMP30) expression in eukaryotic cells: existence of multiple species and membrane localization. PLoS One 2011;6(02):e16545

166 Park H, Ishigami A, Shima T, et al. Hepatic senescence marker protein-30 is involved in the progression of nonalcoholic fatty liver disease. J Gastroenterol 2010;45(04):426-434

167 Ishigami A, Fujita T, Handa S, et al. Senescence marker protein-30 knockout mouse liver is highly susceptible to tumor necrosis factor-alpha- and Fas-mediated apoptosis. Am J Pathol 2002;161 (04):1273-1281

168 Kondo Y, Hasegawa G, Okada H, et al. Lepr(db/db) Mice with senescence marker protein-30 knockout ( $\operatorname{Lepr}(\mathrm{db} / \mathrm{db}) \operatorname{Smp30}(\mathrm{Y} /$ )) exhibit increases in small dense-LDL and severe fatty liver despite being fed a standard diet. PLoS One 2013;8(06):e65698

169 Kondo Y, Masutomi H, Noda Y, et al. Senescence marker protein30/superoxide dismutase 1 double knockout mice exhibit increased oxidative stress and hepatic steatosis. FEBS Open Bio 2014:4:522-532

170 Barnhoorn S, Uittenboogaard LM, Jaarsma D, et al. Cell-autonomous progeroid changes in conditional mouse models for repair endonuclease XPG deficiency. PLoS Genet 2014;10(10):e1004686 
171 Trak-Smayra V, Paradis V, Massart J, Nasser S, Jebara V, Fromenty B. Pathology of the liver in obese and diabetic ob/ob and $\mathrm{db} / \mathrm{db}$ mice fed a standard or high-calorie diet. Int J Exp Pathol 2011;92 (06):413-421

172 Poli G. Pathogenesis of liver fibrosis: role of oxidative stress. Mol Aspects Med 2000;21(03):49-98

173 Lohr K, Pachl F, Moghaddas Gholami A, et al. Reduced mitochondrial mass and function add to age-related susceptibility toward diet-induced fatty liver in C57BL/6J mice. Physiol Rep 2016;4 (19):e12988

174 Kumar A, Sharma A, Duseja A, et al. Patients with nonalcoholic fatty liver disease (NAFLD) have higher oxidative stress in comparison to chronic viral hepatitis. J Clin Exp Hepatol 2013; 3(01):12-18

175 Okuda M, Li K, Beard MR, et al. Mitochondrial injury, oxidative stress, and antioxidant gene expression are induced by hepatitis C virus core protein. Gastroenterology 2002;122(02):366-375

176 Satyanarayana A, Greenberg RA, Schaetzlein S, et al. Mitogen stimulation cooperates with telomere shortening to activate DNA damage responses and senescence signaling. Mol Cell Biol 2004;24(12):5459-5474

177 Kong X, Feng D, Wang H, et al. Interleukin-22 induces hepatic stellate cell senescence and restricts liver fibrosis in mice. Hepatology 2012;56(03):1150-1159

178 Nishizawa H, Iguchi G, Fukuoka H, et al. IGF-I induces senescence of hepatic stellate cells and limits fibrosis in a p53-dependent manner. Sci Rep 2016;6:34605

179 Jin $\mathrm{H}$, Lian N, Zhang F, et al. Activation of PPAR Y/P53 signaling is required for curcumin to induce hepatic stellate cell senescence. Cell Death Dis 2016;7:e2189

180 Wan Y, Meng F, Wu N, et al. Substance P increases liver fibrosis by differential changes in senescence of cholangiocytes and hepatic stellate cells. Hepatology 2017;66(02):528-541

181 Yoshimoto S, Loo TM, Atarashi K, et al. Obesity-induced gut microbial metabolite promotes liver cancer through senescence secretome. Nature 2013;499(7456):97-101

182 Hoare M, Gelson WTH, Das A, et al. CD4+ T-lymphocyte telomere length is related to fibrosis stage, clinical outcome and treatment response in chronic hepatitis C virus infection. J Hepatol 2010;53 (02):252-260

183 Barathan M, Mohamed R, Saeidi A, et al. Increased frequency of late-senescent $T$ cells lacking $C D 127$ in chronic hepatitis $C$ disease. Eur J Clin Invest 2015;45(05):466-474

184 Zhou Y, Li GY, Ren JP, et al. Protection of CD4+ T cells from hepatitis C virus infection-associated senescence via $\Delta$ Np63-miR-181a-Sirt1 pathway. J Leukoc Biol 2016;100(05):1201-1211

185 Schirdewahn T, Grabowski J, Owusu Sekyere S, et al. The third signal cytokine interleukin 12 rather than immune checkpoint inhibitors contributes to the functional restoration of hepatitis D virus-specific T cells. J Infect Dis 2017;215(01):139-149

186 Gelson W, Hoare M, Vowler S, et al. Features of immune senescence in liver transplant recipients with established grafts. Liver Transpl 2010;16(05):577-587

187 Sagiv A, Burton DGA, Moshayev Z, et al. NKG2D ligands mediate immunosurveillance of senescent cells. Aging (Albany NY) 2016; 8(02):328-344

188 Ovadya Y, Krizhanovsky V. Senescent cells: SASPected drivers of age-related pathologies. Biogerontology 2014;15(06):627-642

189 Kwon Y, Kim JW, Jeoung JA, Kim MS, Kang C. Autophagy is prosenescence when seen in close-up, but anti-senescence in longshot. Mol Cells 2017;40(09):607-612

190 Grosse L, Wagner N, Emelyanov A, et al. Defined p16High senescent cell types are indispensable for mouse healthspan. Cell Metab 2020;S1550-4131(20):30241-30242

191 Maeso-Díaz R, Ortega-Ribera M, Fernández-Iglesias A, et al. Effects of aging on liver microcirculatory function and sinusoidal phenotype. Aging Cell 2018;17(06):e12829
192 Koudelkova P, Weber G, Mikulits W. Liver sinusoidal endothelial cells escape senescence by loss of p19ARF. PLoS One 2015;10 (11):e0142134

193 Eggert T, Wolter K, Ji J, et al. Distinct functions of senescenceassociated immune responses in liver tumor surveillance and tumor progression. Cancer Cell 2016;30(04):533-547

194 Yang D, Li L, Liu H, et al. Induction of autophagy and senescence by knockdown of ROC1 E3 ubiquitin ligase to suppress the growth of liver cancer cells. Cell Death Differ 2013;20(02): 235-247

195 Zhu R, Mok MT, Kang W, et al. Truncated HBx-dependent silencing of GAS2 promotes hepatocarcinogenesis through deregulation of cell cycle, senescence and p53-mediated apoptosis. J Pathol 2015;237(01):38-49

196 Sasaki M, Nakanuma Y. New concept: cellular senescence in pathophysiology of cholangiocarcinoma. Expert Rev Gastroenterol Hepatol 2016;10(05):625-638

197 Plentz RR, Park YN, Lechel A, et al. Telomere shortening and inactivation of cell cycle checkpoints characterize human hepatocarcinogenesis. Hepatology 2007;45(04):968-976

198 MacDonald RA. "Lifespan" of liver cells. Autoradio-graphic study using tritiated thymidine in normal, cirrhotic, and partially hepatectomized rats. Arch Intern Med 1961;107:335-343

199 Michalopoulos GK, DeFrances MC. Liver regeneration. Science 1997;276(5309):60-66

200 Ritschka B, Knauer-Meyer T, Gonçalves DS, et al. The senotherapeutic drug ABT-737 disrupts aberrant p21 expression to restore liver regeneration in adult mice. Genes Dev 2020;34(78):489-494

201 Sanz N, Díez-Fernández C, Alvarez AM, Fernández-Simón L, Cascales M. Age-related changes on parameters of experimentally-induced liver injury and regeneration. Toxicol Appl Pharmacol 1999;154(01):40-49

202 Tsukamoto I, Nakata R, Kojo S. Effect of ageing on rat liver regeneration after partial hepatectomy. Biochem Mol Biol Int 1993;30(04):773-778

203 Fry M, Silber J, Loeb LA, Martin GM. Delayed and reduced cell replication and diminishing levels of DNA polymerase-alpha in regenerating liver of aging mice. J Cell Physiol 1984;118(03): 225-232

204 Albrecht JH, Meyer AH, Hu MY. Regulation of cyclin-dependent kinase inhibitor p21(WAF1/Cip1/Sdi1) gene expression in hepatic regeneration. Hepatology 1997;25(03):557-563

205 Albrecht JH, Poon RY, Ahonen CL, Rieland BM, Deng C, Crary GS. Involvement of p21 and p27 in the regulation of CDK activity and cell cycle progression in the regenerating liver. Oncogene 1998; 16(16):2141-2150

206 Pujol MJ, Jaime M, Serratosa J, Jaumot M, Agell N, Bachs O. Differential association of p21Cip1 and p27Kip1 with cyclin E-CDK2 during rat liver regeneration. J Hepatol 2000;33(02):266-274

207 Jaime M, Pujol MJ, Serratosa J, et al. The p21(Cip1) protein, a cyclin inhibitor, regulates the levels and the intracellular localization of CDC25A in mice regenerating livers. Hepatology 2002; 35(05):1063-1071

208 Lu WY, Bird TG, Boulter L, et al. Hepatic progenitor cells of biliary origin with liver repopulation capacity. Nat Cell Biol 2015;17 (08):971-983

209 Raven A, Lu WY, Man TY, et al. Cholangiocytes act as facultative liver stem cells during impaired hepatocyte regeneration. Nature 2017;547(7663):350-354

210 Jin $\mathrm{H}$, Lian N, Zhang F, et al. Inhibition of YAP signaling contributes to senescence of hepatic stellate cells induced by tetramethylpyrazine. Eur J Pharm Sci 2017;96:323-333

211 Panebianco C, Oben JA, Vinciguerra M, Pazienza V. Senescence in hepatic stellate cells as a mechanism of liver fibrosis reversal: a putative synergy between retinoic acid and PPAR-gamma signalings. Clin Exp Med 2017;17(03):269-280 
212 Zhang Z, Yao Z, Zhao S, et al. Interaction between autophagy and senescence is required for dihydroartemisinin to alleviate liver fibrosis. Cell Death Dis 2017;8(06):e2886

213 Wang C, Vegna S, Jin H, et al. Inducing and exploiting vulnerabilities for the treatment of liver cancer. Nature 2019;574 (7777):268-272

214 Ovadya Y, Krizhanovsky V. Strategies targeting cellular senescence. J Clin Invest 2018;128(04):1247-1254

215 Fontana L, Nehme J, Demaria M. Caloric restriction and cellular senescence. Mech Ageing Dev 2018;176:19-23

216 Munoz-Espin D. Nanocarriers targeting senescent cells. Transl Med Aging. 2019;3:1-5

217 Sidler C, Kovalchuk O, Kovalchuk I. Epigenetic regulation of cellular senescence and aging. Front Genet 2017;8:138
218 Yang N, Sen P. The senescent cell epigenome. Aging (Albany NY) 2018;10(11):3590-3609

219 Horvath S, Erhart W, Brosch M, et al. Obesity accelerates epigenetic aging of human liver. Proc Natl Acad Sci U S A 2014;111 (43):15538-15543

220 Prattichizzo F, Bonafè M, Olivieri F, Franceschi C. Senescence associated macrophages and "macroph-aging": are they pieces of the same puzzle? Aging (Albany NY) 2016;8(12):3159-3160

221 Goto M. Inflammaging (inflammation + aging): a driving force for human aging based on an evolutionarily antagonistic pleiotropy theory? Biosci Trends 2008;2(06):218-230

222 Baylis D, Bartlett DB, Patel HP, Roberts HC. Understanding how we age: insights into inflammaging. Longev Healthspan 2013;2 $(01): 8$ 